\title{
Nucleosome-binding activities within JARID2 and EZH1 regulate the function of PRC2 on chromatin
}

\author{
Jinsook Son, ${ }^{1}$ Steven S. Shen, ${ }^{1,2}$ Raphael Margueron, ${ }^{1,3}$ and Danny Reinberg ${ }^{1,4}$ \\ ${ }^{1}$ Howard Hughes Medical Institute, Department of Biochemistry and Molecular Pharmacology, New York University School \\ of Medicine, New York, New York 10016, USA; ${ }^{2}$ Center for Health Informatics and Bioinformatics, New York University School \\ of Medicine, New York, New York 10016, USA
}

Polycomb-repressive complex 2 (PRC2) comprises specific members of the Polycomb group of epigenetic modulators. PRC2 catalyzes methylation of histone $\mathrm{H} 3$ at Lys 27 (H3K27me3) through its Enhancer of zeste (Ezh) constituent, of which there are two mammalian homologs: Ezh1 and Ezh2. Several ancillary factors, including Jarid2, modulate PRC2 function, with Jarid2 facilitating its recruitment to target genes. Jarid2, like Ezh2, is present in poorly differentiated and actively dividing cells, while Ezh1 associates with PRC2 in all cells, including resting cells. We found that Jarid2 exhibits nucleosome-binding activity that contributes to PRC2 stimulation. Moreover, such nucleosome-binding activity is exhibited by PRC2 comprising Ezh1 (PRC2-Ezh1), in contrast to PRC2-Ezh2. The presence of Ezh1 helps to maintain PRC2 occupancy on its target genes in myoblasts where Jarid2 is not expressed. Our findings allow us to propose a model in which PRC2-Ezh2 is important for the de novo establishment of H3K27me3 in dividing cells, whereas PRC2-Ezh1 is required for its maintenance in resting cells.

[Keywords: EZH1; EZH2; JARID2; PRC2; Polycomb]

Supplemental material is available for this article.

Received July 8, 2013; revised version accepted November 4, 2013.

Polycomb group (PcG) proteins are evolutionarily conserved transcriptional regulators that function via putative epigenetic processes (Margueron and Reinberg 2011). These proteins exhibit a critical role in major developmental pathways, stem cell differentiation, and cancer (Schuettengruber et al. 2007). Polycomb-repressive complex 1 (PRC1) and PRC2 are two complexes comprising specific PcG proteins that are key to maintaining transcriptional repression for various target genes, with the best known being the homeotic genes (Lewis 1978; Jacobs and van Lohuizen 1999). Mammalian PRC2 consists of four core components: Enhancer of zeste (Ezh), Embryonic ectoderm development (Eed), Suppressor of zeste 12 homolog (Suz12), and RbAp46/48 (Cao et al. 2002; Kuzmichev et al. 2002). The Ezh component contains a SET domain that exhibits histone lysine methyltransferase (HMT) activity directed toward histone H3 Lys 27 (H3K27). While Ezh is the catalytic subunit, it functions as such only when contained within PRC2. Eed plays a role as a scaffold protein that, through its $\mathrm{N}$-terminal region,

\footnotetext{
${ }^{3}$ Present address: Institut Curie/INSERM U934/CNRS UMR 3215, 26 , rue d'Ulm, 75005 Paris, France.

${ }^{4}$ Corresponding author

E-mail danny.reinberg@nyumc.org

Article is online at http://www.genesdev.org/cgi/doi/10.1101/gad.225888.113.
}

physically links PRC2 to its $\mathrm{H} 3$ substrates (Montgomery et al. 2005; Tie et al. 2007). The C terminus of Eed is composed of WD40 repeats that, while represented in a number of other proteins, are arranged in the case of Eed such that an aromatic cage is established that can bind transcriptionally repressive, methylated lysine residues, resulting in an allosteric effect that significantly enhances PRC2 activity (Margueron et al. 2009). Suz12 is necessary for Ezh stability (Pasini et al. 2004, 2007). Last, the $\mathrm{RbAp} 46 / 48$ components are known to bind histones H3 and H4 (Vermaak et al. 1999; Murzina et al. 2008; Schmitges et al. 2011).

The Ezh constituent of PRC2 exists as two homologs in mammals: Ezh1 and Ezh2 (Laible et al. 1997). Interestingly, Ezh1 is ubiquitously expressed, while Ezh2 is expressed in actively dividing cells such that Ezhl is the predominant species upon terminal differentiation (Laible et al. 1997; Visser et al. 2001; Margueron et al. 2008). While PRC2 comprising either Ezh1 (PRC2-Ezh1) or Ezh2 (PRC2-Ezh2) exhibits H3K27 methyltransferase

(C) 2013 Son et al. This article is distributed exclusively by Cold Spring Harbor Laboratory Press for the first six months after the full-issue publication date (see http://genesdev.cshlp.org/site/misc/terms.xhtml). After six months, it is available under a Creative Commons License (AttributionNonCommercial 3.0 Unported), as described at http://creativecommons.org/ licenses/by-nc/3.0/. 
activity, the level of this activity is markedly reduced in the case of PRC2-Ezh1. On the other hand, PRC2-Ezh1 functions directly in chromatin compaction, while PRC2-Ezh2 is devoid of such activity (Margueron et al. 2008). Given these striking distinctions in both the expression profiles and the inherent activities exhibited by Ezh1 and Ezh2, we proposed that PRC2 shifts gears in its key roles, as a function of differentiation (Margueron et al. 2008; Margueron and Reinberg 2011; this study). In actively dividing undifferentiated cells containing Ezh1 and Ezh2, PRC2 is required to establish the transcriptionally repressive $\mathrm{H} 3 \mathrm{~K} 27 \mathrm{me} 3$ modification, with this process involving recognition of $\mathrm{H} 3 \mathrm{~K} 27 \mathrm{me} 3$ through its Eed subunit and propagation of $\mathrm{H} 3 \mathrm{~K} 27 \mathrm{me} 3$ through the robust HMT activity of Ezh2. In contrast, in cells undergoing and completing the differentiation process, PRC2 comprises mainly Ezh1 and is active in chromatin compaction, again through Eed recognition of H3K27me3.

While the target (H3K27) of PRC2 catalytic activity and the resultant product (H3K27me) are well documented, none of the mammalian PRC2 core components appear to exhibit DNA-binding specificity based on the results of numerous studies seeking the means by which mammalian PRC2 is recruited to its target genes. Additionally, mammalian PRC2 apparently fails to interact with sequence-specific DNA-binding proteins that could account for its recruitment (Margueron and Reinberg 2011; Voigt et al. 2013). The case in Drosophila differs in that Drosophila Pho is a sequence-specific DNA-binding protein that interacts with and recruits Drosophila PRC2 to Polycomb response elements (PRE) (Brown et al. 1998). The evidence supporting such a role for the mammalian homolog of Pho, YY1, in PRC2 recruitment is inconsistent, however, and cannot account for the various mammalian PRC2 targets (Wang et al. 2004).

Jarid2 was identified as a factor that contributes to mammalian PRC2 recruitment to its target genes (Peng et al. 2009; Shen et al. 2009; Landeira et al. 2010; Li et al. 2010; Pasini et al. 2010). Jarid2 is the founding member of the Jumonji family of proteins containing a Jumonji C (JmjC) domain. However, unlike other JmjC-containing proteins that function as histone demethylases (Klose et al. 2006; Christensen et al. 2007), Jarid2 is devoid of such activity, as it lacks the residues essential for binding of the requisite cofactors (Takeuchi et al. 2006). In light of Jarid2 interaction with Ezh2 and Suz12 subunits (Peng et al. 2009; Li et al. 2010), genome-wide studies revealed that Jarid2 occupancy overlaps a significantly large number of PRC2 target sites. Jarid2 knockdown resulted in reduced PRC2 recruitment to its target genes and vice versa, suggesting that Jarid2 and PRC2 are interdependent for recruitment (Peng et al. 2009; Shen et al. 2009; Li et al. 2010). In addition, Jarid2 knockdown is required for proper embryonic stem (ES) cell differentiation (Li et al. 2010; Pasini et al. 2010). More evidence bolstering that Jarid2 is critical for PRC2 recruitment came from the realization that the Jarid2 AT-rich interaction domain (ARID) and zinc finger domains function as DNA-binding motifs with low affinity to CG-rich regions, with these regions showing a high correlation with PRC2 localiza- tion in a genome-wide study (Bernstein et al. 2006; Li et al. 2010). Importantly, GC-rich sequences ectopically incorporated into the ES cell genome are capable of recruiting PRC2 (Mendenhall et al. 2010).

While Jarid2 has demonstrable effects on PRC2 recruitment, other PRC2-interacting proteins can alter its enzymatic activity. Adipocyte enhancer-binding protein 2 (Aebp2) is recognized as a DNA-binding protein (Kim et al. 2009); however, its role in PRC2 recruitment has not been extensively studied. Instead, Aebp2 has been shown to stimulate the core PRC2 enzymatic activity, and this stimulatory effect might be due to its ability to bind nucleosomes (Cao and Zhang 2004), but this remains unreported.

Several independent studies are in accord regarding an important role for Jarid2 in PRC2 recruitment to its targets, yet discrepancies exist regarding its role in regulating $\mathrm{PRC} 2$ enzymatic activity, with some reports indicating a Jarid2-mediated stimulatory effect on its HMT activity (Li et al. 2010; Zhang et al. 2011), and others indicating an inhibitory effect (Peng et al. 2009; Shen et al. 2009). This controversy prompted us to undertake a thorough analysis of the HMT activity of PRC2, particularly in the context of Jarid2. We also examined the role of Jarid2 as a consequence of the Ezh species comprising PRC2 (given that the expression of Ezh2 and of Jarid2 declines upon differentiation) as well as the distinctive activities exhibited by PRC2 when comprising Ezh2 versus Ezh1.

Our findings reveal that PRC2 requirements for Jarid2 differ depending on the identity of its Ezh homolog. This distinction arises from the previously unrecognized nucleosome-binding activity inherent to both Jarid2 and Ezh1. Based on such activity, Ezh1 can partially compensate for the natural absence of Jarid2 in partially differentiated myoblast cells to enable optimal PRC2-Ezh2 recruitment. That Jarid2 and Ezh1 converge on PRC2Ezh2 in this manner is consistent with their inverse expression profiles as a function of differentiation.

\section{Results}

\section{Minimal Jarid2 domain required for PRC2-Ezh2 stimulation}

To ascertain the molecular basis underlying Jarid2-mediated regulation of PRC2-Ezh2 activity, we first optimized the biochemical parameters for its HMT activity using nucleosomal substrate in vitro, as a function of Jarid2, and in comparison with a known stimulatory factor, Aebp2 (Cao and Zhang 2004). Figure 1 shows the levels of PRC2-Ezh2 activity obtained during a time course as a function of the presence of either Jarid2 or Aebp2 (Fig. 1A), upon increased concentrations of the cofactor $S$-adenosylmethionine (SAM) as a function of the presence of Jarid2 and/or Aebp2 (Fig. 1B; see also Supplemental Fig. 1 ), and upon increasing amounts of Jarid2 or Aepb2 (Fig. 1C). In all cases, the stimulatory effect of Jarid2 was markedly greater relative to that of Aebp2, and the addition of both factors stimulated PRC2-Ezh2 activity 

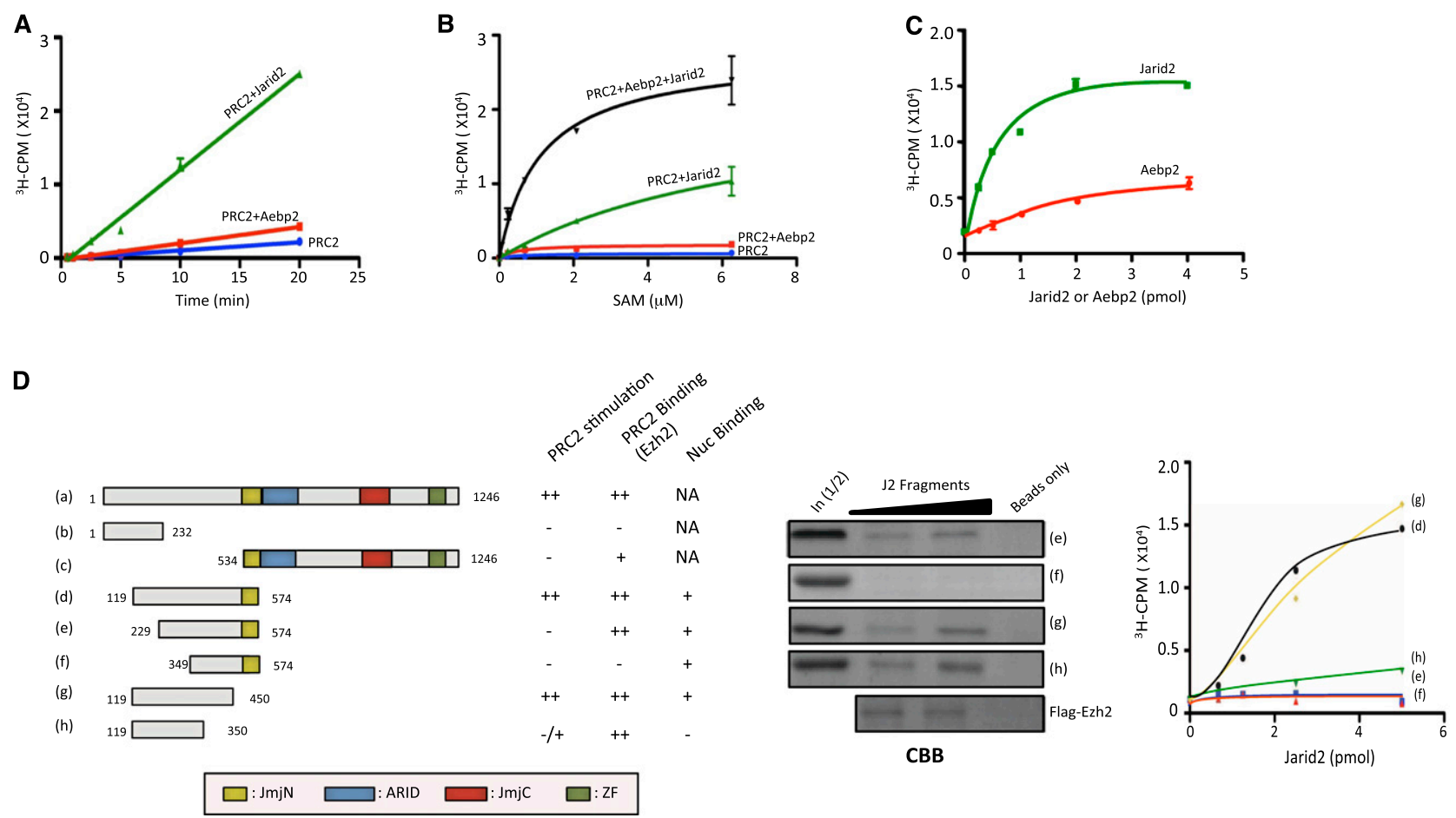

Figure 1. Minimal Jarid2 regions regulating PRC2. (A) Time course of an HMT assay using 0.67 pmol of PRC2 either alone or with 4 pmol of Aebp2 or 1 pmol of Jarid2 on 2.28 pmol of recombinant nucleosomes. The assay was incubated with $12.5 \mu M$ SAM (radiolabeled:cold $=1: 45$ ) and analyzed by scintillation counting after SDS-PAGE. $(B)$ HMT assay performed with increasing amounts $(0.39-6.25 \mu \mathrm{M})$ of SAM in the presence of PRC2 either alone or with Aebp2 and/or Jarid2 using recombinant nucleosomes as in $A$. (C) HMT assay performed with increasing amounts of Jarid2 or Aebp2 with PRC2 as in $A$. (D, left panel) Schematic representation of fulllength Jarid2 and protein fragments analyzed for PRC2 stimulation, Ezh2 binding, and nucleosome binding. The previously characterized Jarid2 domains are also shown: Jumonji $\mathrm{N}$ (JmjN) (yellow), JmjC (red), ARID (blue), and zinc finger (ZF) (green). (Middle panel) Coomassie blue staining of a pull-down assay using Flag-tagged Ezh2 and Jarid2 protein fragments as shown in the left panel. Results of pull-down assays performed with Jarid2 protein fragments and Flag-tagged Ezh2 after Coomassie blue staining. (Right panel) HMT assay using $2.28 \mathrm{pmol}$ of recombinant nucleosomes and $0.67 \mathrm{pmol}$ of PRC2 either alone or with increasing amounts (0.68-5 pmol) of candidate Jarid2 fragments (designated with letters) as shown in the left panel.

in a synergistic manner (Fig. 1B). Of note, the initial rate of PRC2-Ezh2 catalysis was significantly stimulated in the case of Jarid2, whereas Aebp2 was barely effectual in this regard (Fig. 1A).

Having established conditions necessary for optimal PRC2-Ezh2 activity, we next determined the minimal Jarid2 domain necessary for optimal stimulation. Truncated versions of Jarid2 (Fig. 1D, left panel) were tested for interaction with Ezh2 in pull-down assays (Fig. 1D, middle panel) and in HMT assays performed with PRC2-Ezh2 (Fig. 1D, right panel). While Jarid2 fragment h (119-350 amino acids) was the minimal domain required for Ezh2 binding, it was markedly defective in PRC2-Ezh2 stimulatory activity. Similarly, fragment e (229-574 amino acids) retained the ability to bind PRC2 but not the ability to stimulate its activity. The minimal domain required for both Ezh2 binding and optimal PRC2-Ezh2 stimulation was contained within fragment g (119-450 amino acids). That this optimal stimulation required the Ezh2 interaction domain is evidenced by the results obtained with fragment $\mathrm{f}$ (349-574 amino acids). These findings indicate that, while necessary, Jarid2 binding to Ezh2 is not sufficient to recapitulate its stimulation of PRC2Ezh2 HMT activity.

\section{Jarid2 binds nucleosomes promoting PRC2-Ezh2 association}

The distinction between Jarid2- and Aebp2-mediated stimulation during the initial rate of PRC2-Ezh2 catalysis (Fig. 1A) might stem from differences in their effects on PRC2-Ezh2 substrate binding. Indeed, the extent of Aebp2 stimulation was elevated when PRC2 was preincubated with nucleosomal substrate (Supplemental Fig. 2A). We next compared Jarid2 and Aebp2 for effects on PRC2-Ezh2 substrate binding using a biotin-labeled nucleosome-binding assay (Fig. 2A, top). PRC2-Ezh2 nucleosome-binding activity was barely detectable when alone, and the presence of Aebp2 was ineffectual in this regard. However, Jarid2 markedly enhanced such binding (Fig. 2A, bottom). The addition of both Aebp2 and Jarid2 did not further enhance PRC2-Ezh2 binding relative to the addition of Jarid2 alone, although Aebp2 association with the nucleosomes was now detectable, likely due to 
A

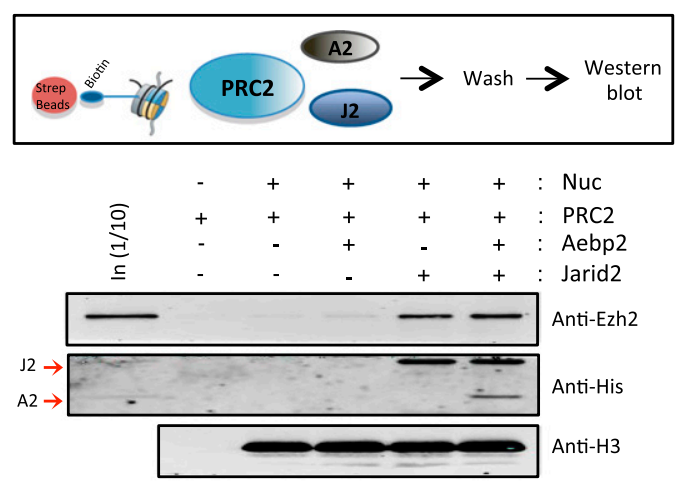

C

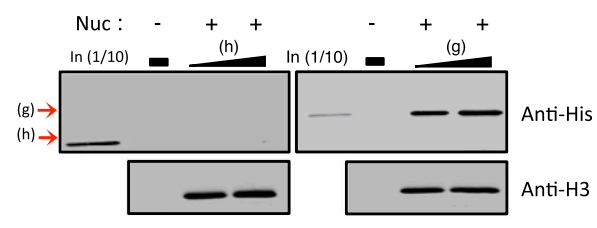

D

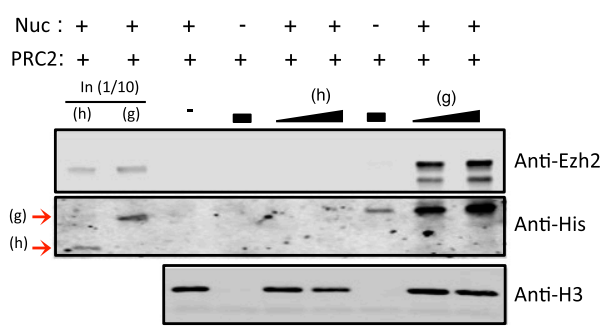

$\mathbf{B}$
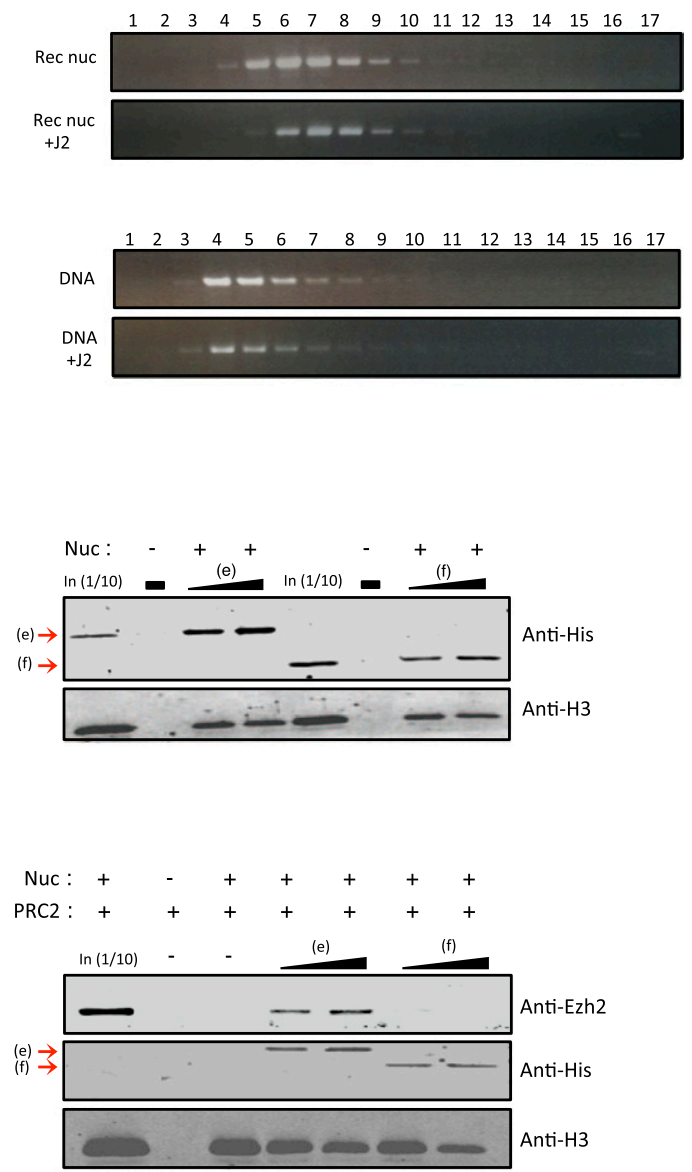

Figure 2. Jarid2 interacts directly with nucleosomes, promoting PRC2 interaction. (A) Nucleosome-binding assay using biotin mononucleosomes and PRC2 in the presence of His-Aebp2 and/or His-Jarid2 and analyzed by Western blot using anti-Ezh2, anti-His tag, or anti-H3 antibody. (B) Sucrose gradient sedimentation assay using either nucleosomes or DNA with Jarid2 fragment g. (C) Nucleosome-binding assay using biotin mononucleosomes and His-Jarid2 fragments (as shown in Fig. 1D) followed by Western blot using anti-His tag or anti-H3 antibody. $(D)$ Nucleosome-binding assay as in $A$ using the Jarid2 fragments indicated.

its association with PRC2-Ezh2, which now exhibited nucleosome binding in the presence of Jarid2. This finding is in keeping with the differential effects of these two factors during the initial rate of the HMT reaction.

We next examined whether Jarid2 itself can directly bind to nucleosomes, thereby stabilizing PRC2-Ezh2 association. Although Jarid2 exhibits DNA-binding activity (Li et al. 2010), its fragment $\mathrm{g}$ is devoid of the domain responsible for such binding yet exhibits both Ezh2 binding and stimulation of PRC2-associated HMT activity, as shown above. Thus, we performed sucrose gradient sedimentation assays using Jarid2 fragment $g$ along with either recombinant nucleosomes or DNA. Jarid2 fragment $g$ interacted with nucleosomes but not with DNA alone, as evidenced by the shift in the sedimentation pattern in the case of the former but not the latter (Fig. 2B). Similar experiments performed with Aebp2 failed to demonstrate its interaction with nucleo- somes or DNA (Supplemental Fig. 2B; data not shown). Thus, Jarid2 exhibits a previously unrecognized nucleosome-binding activity that is independent of its DNAbinding domain and through which it promotes PRC2 association with its substrate.

The Jarid2 fragments analyzed above for Ezh2-binding activity and stimulation of PRC2-Ezh2 HMT activity (Fig. 1D) were next compared to determine the minimal Jarid2 domain required for its nucleosome-binding activity in pull-down assays (Fig. 2C). Fragments e-g containing Jarid2 349-450 amino acids all retained nucleosomebinding activity, while fragment $\mathrm{h}$ lacking this region was devoid of the activity. In addition, gel mobility shift assays support that Jarid2 $349-450$ amino acids is necessary for nucleosome binding (Supplemental Fig. 2C). Not surprisingly, fragment $h$ did not enhance PRC2Ezh2 binding to nucleosomes and neither did fragment $f$ (Fig. 2D), which had failed to interact with Ezh2 (Fig. 1D). However, consistent with their interaction with nucleo- 
somes and Ezh2 (Fig. 1D), fragments e and g did enhance PRC2-Ezh2 binding to nucleosomes (Fig. 2D).

\section{Distinct Jarid2 requirements as a consequence of distinct Ezh homologs}

PRC2 exhibits notable differences in activity depending on the Ezh homolog that it harbors. While PRC2-Ezh2 and PRC2-Ezh1 both exhibit HMT activity, the levels of such catalysis are markedly elevated in vitro and in vivo in the case of PRC2-Ezh2 relative to that of PRC2-Ezh1 (Fig. 3A; Margueron et al. 2008). Moreover, PRC2-Ezh1 is distinctly capable of compacting chromatin (Margueron et al. 2008). Guided by our findings in the previous sections showing the impact of Jarid2 on PRC2-Ezh2 association with nucleosomes and on its HMT activity and the fact that fragment $\mathrm{g}$ retains Jarid2 interaction with Ezh2, its PRC2-Ezh2 stimulatory activity, and its nucleosome-binding activity, we next compared the effects of fragment $\mathrm{g}$ in the context of Ezh1 versus Ezh2. Jarid2 fragment $g$ interacted equally well with highly purified Flag-tagged versions of either Ezh1 or Ezh2 (Supplemental Fig. 3A) in Flag pull-down assays (Fig. 3B). We next compared the extent of Jarid2-mediated stimulation and found that Jarid2 fragment $g$ was effective in stimulating the HMT activity of PRC2-Ezh1 (Fig.
A

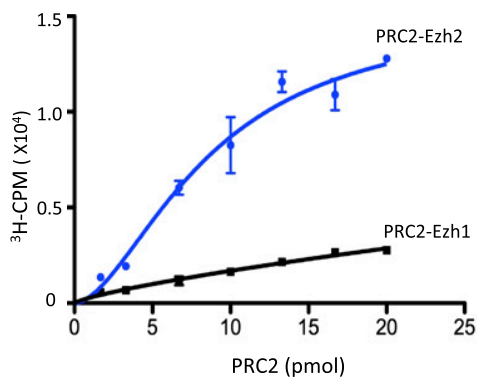

C
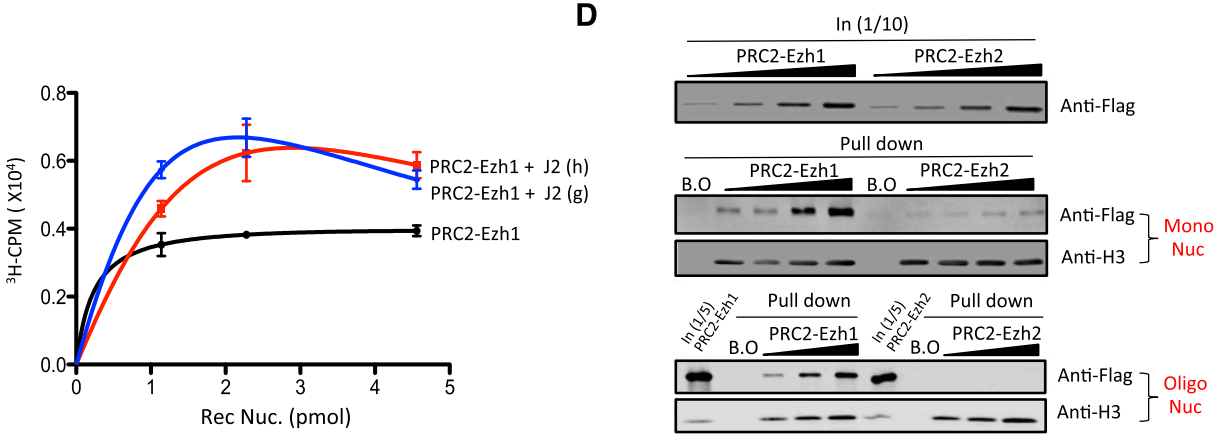

D

B

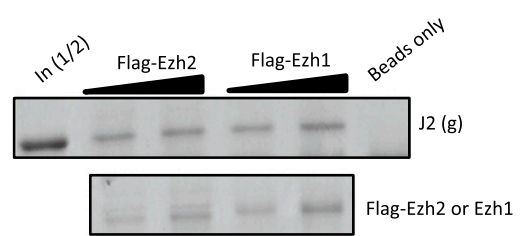

$\mathbf{F}$
E

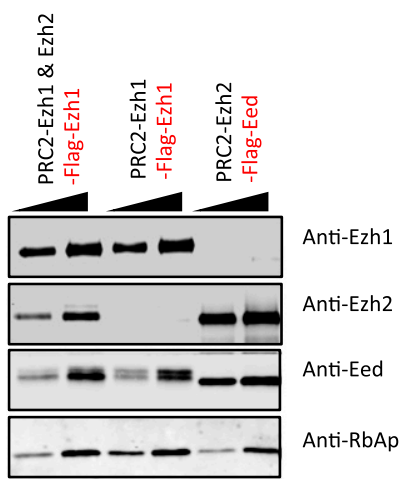

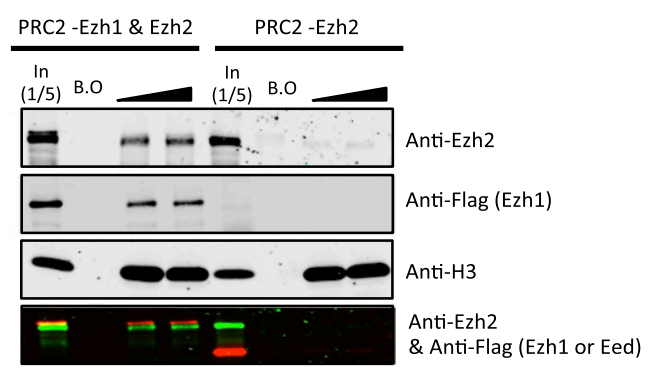

Figure 3. PRC2 nucleosome-binding activity is enhanced when comprising Ezh1. (A) HMT assay performed with increasing amounts (1.67-20 pmol) of PRC2 containing either Ezh1 or Ezh2, as indicated. (B) Results of pull-down assays using Flag-tagged versions of Ezh1 or Ezh2 and Jarid2 fragment g after Coomassie blue staining. $(C)$ HMT assay using 3.34 pmol of PRC2-Ezh1 in the absence or presence of $5 \mathrm{pmol}$ of Jarid2 fragment $\mathrm{g}$ or h with increasing amounts of recombinant nucleosomes. $(D)$ Western blot analysis of nucleosomebinding assays performed with increasing amounts (3.34-26.72 pmol) of either PRC2-Ezh1 or PRC2-Ezh2 using biotin mono- or oligonucleosomes and anti-Flag or anti-H3 antibody. (E) Western blot analysis of increasing amounts of PRC2-Ezh1, PRC2-Ezh2, or PRC2Ezh1/Ezh2 using the antibodies indicated at the right. $(F)$ Nucleosome-binding assay with increasing amounts of PRC2-Ezh1/Ezh2 using biotin mononucleosomes as in $D$. The signal for anti-Flag is shown in red, and the signal for anti-Ezh2 is in green. 
3C). Given that Jarid2 fragment h retained Ezh2 interaction but was devoid of Jarid2 nucleosome-binding activity, we also compared its effects on PRC2-Ezh1 relative to that of fragment g. Surprisingly, and in contrast to the case of PRC2-Ezh2, Jarid2 fragments $g$ and h functioned equally well in the case of PRC2-Ezh1. This intriguing difference in the functioning of Jarid2 fragment $h$ in the context of the specific Ezh homolog comprising PRC2 points to distinctive Jarid2 requirements in PRC2 regulation.

\section{Ezh1 conveys nucleosome-binding activity to PRC2}

Since Jarid2 fragment $\mathrm{h}$ lacks the Jarid2 nucleosomebinding activity important for PRC2-Ezh2 stimulation yet is equally as effective as fragment $\mathrm{g}$ in the case of PRC2-Ezh1, we reasoned that Ezh1 may compensate for this fragment $h$ defect, especially in light of its chromatin compaction capability when comprising PRC2. Indeed, in the absence of Jarid2 and in contrast to PRC2-Ezh2 alone, PRC2-Ezh1 alone interacts with both mono- and oligonucleosomes in pull-down assays (Fig. 3D), suggesting that Jarid2 is dispensable for PRC2-Ezh1 association with nucleosomes under these conditions.

While the compositional subunits of PRC2 are known, the exact ratio of its constituents awaits high-resolution structural analyses. However, given that viral SET domain proteins have been shown to dimerize and that Ezh1 coimmunoprecipitates with Ezh2 in the case of 293 cells (Margueron et al. 2008), it is likely that either PRC2 comprises an Ezh1/2 heterodimer or PRC2-Ezh1 and PRC2-Ezh2 can exist as a dimer in cells. Thus, we next examined whether PRC2-Ezh1/2 would be capable of nucleosome binding in the absence of Jarid2. PRC2 was reconstituted by coinfecting SF9 cells with Flagtagged Ezh1, untagged Ezh2, and the remaining PRC2 core components. The Flag affinity-purified PRC2 complex exhibited the presence of untagged Ezh2 together with Flag-tagged Ezh1 and other core components, indicating that PRC2 could comprise both Ezh homologs (Fig. 3E). Moreover, given the presence of Ezh1, this version of PRC2 retained nucleosome-binding activity (Fig. 3F).

To fully understand this sharp distinction between the nucleosome-binding capabilities of Ezh1 and Ezh2, we focused on a further analysis of their functional domains. Figure 4A shows a schematic representation of Ezh1 and Ezh2 featuring the domains required for PRC2 HMT activity (SET) and for Ezh interaction with other core PRC2 components (Eed and Suz12) as indicated. The Ezh homologs diverge in an extensive region C-terminal to the Eed interaction domain. Thus, we first investigated whether this region is responsible for the Jarid2 compensatory activity exhibited by Ezh1 by generating Ezh chimeras within the context of Ezh2 and therefore the Ezh2 SET domain (Fig. 4A). Recombinant PRC2 complexes comprising either Ezh1 or the three chimeras were isolated from SF9 cells (Fig. 4B,C) and compared for nucleosome-binding activity. Chimera 3 containing the entire Ezh1-specific domain was the only candidate to attain nucleosome-binding activity comparable with that of Ezh1 (Fig. 4D).

Since our findings revealed that Jarid2 nucleosomebinding activity mediates its stimulatory effect on PRC2Ezh2 enzymatic activity (Figs. 1D, 2D) and that chimera 3 retains Ezh1-associated nucleosome-binding activity, we next compared PRC2 enzymatic activity as a consequence of Ezh1, Ezh2, and chimera 3. As expected, PRC2-Ezh2 HMT activity is considerably greater than that of PRC2Ezh1; however, chimera 3 containing the Ezh2 SET domain and Ezh1 nucleosome-binding activity imparted even higher levels of HMT activity to PRC2 (Fig. 4E). Of note, the Km of the HMT reaction was decreased in the case of chimera 3 compared with PRC2-Ezh2 (Fig. 4E), which is in line with its nucleosome-binding activity (Fig. 4D). Importantly, this Ezh1-specific nucleosome-binding activity also conferred Jarid2 compensatory function to chimera 3, as evidenced by the similar extent of its stimulation by Jarid2 fragments $g$ and $h$ (Fig. 4F). That fragments $g$ and $h$ exhibit a similar and mild stimulatory effect irrespective of Jarid2 nucleosome-binding activity was also observed in the case of recombinant PRC2-Ezh1 (Fig. 3C) and is suggestive of a Jarid2-mediated allosteric effect. Nonetheless, the results here show that Ezh1specific nucleosome-binding activity promoted Ezh2associated HMT activity in a manner similar to that of Jarid2.

\section{Jarid2-deficient myoblasts exhibit Ezh1 dependency for PRC2 recruitment}

Thus far, this study established that Jarid2 inherently contains nucleosome-binding activity that promotes its PRC2-Ezh2 partner to associate with its substrates, thereby elevating its HMT activity. Moreover, this Jarid2 function is obviated by the nucleosome-binding activity inherent to Ezh1. We next sought to understand how these intertwined functions relate to the biological role of the Ezh constituents of PRC2. To our knowledge, there are no reports of natural cellular contexts in which Ezh1 is barely detectable. However, there are natural circumstances during which cellular Jarid2 is undetectable. Therefore, we examined such conditions to determine whether Ezh1 would now be critical to PRC2 recruitment.

A previous study demonstrated that Ezh1 and Ezh2 are abundant in myoblasts and that the levels of Ezh2 dramatically decrease upon their differentiation into myotubes (Stojic et al. 2011). Indeed, Western blot analysis confirms the abundance of Ezh1 and Ezh2 expression in extracts of C2C12 myoblasts and low levels of Ezh2 expression in extracts of myotubes (Fig. 5A). As a control and a gauge for Jarid2 expression, extracts of ES cells containing floxed Jarid2 alleles before and after Jarid2 knockout were probed by Western analysis and compared with the expression of Jarid2 in myoblasts. Jarid2 is undetectable in C2C12 cells (Fig. 5B). This Jarid2 deficiency is also reflected by the results obtained with chromatin immunoprecipitation (ChIP)qPCR analysis of C2C12 myoblasts (Fig. 5C). However, both Ezh1 and Ezh2 were present at their expected target 
A

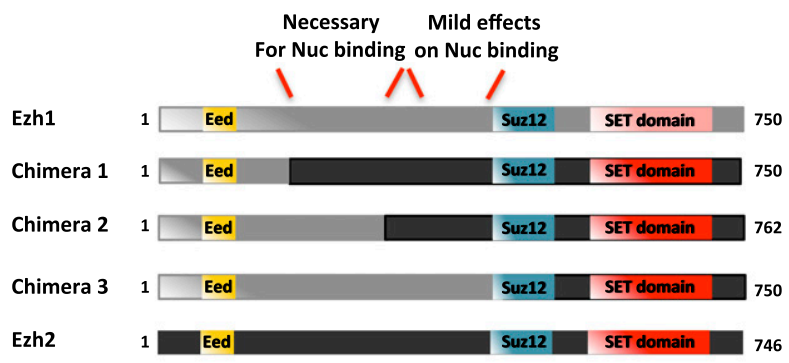

B

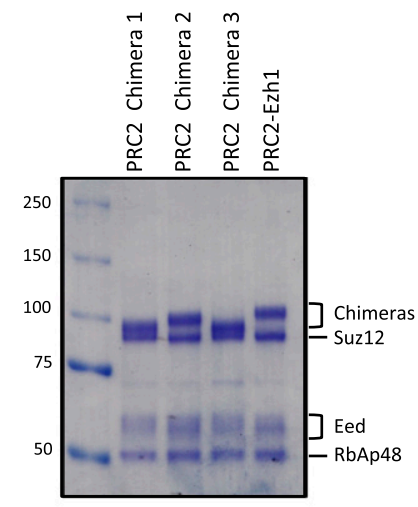

C

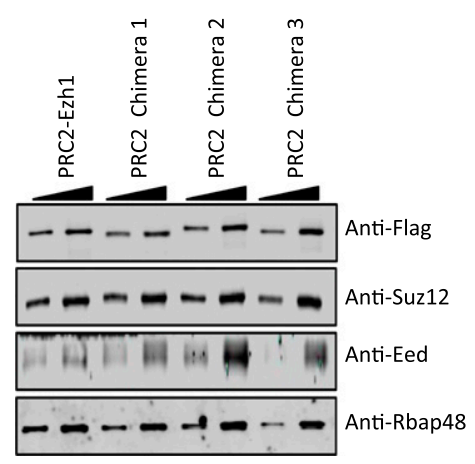

$\mathbf{E}$

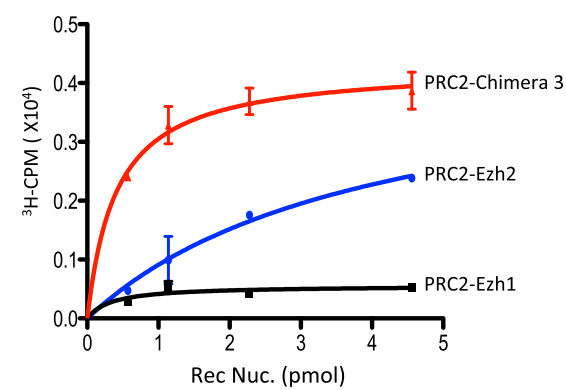

D

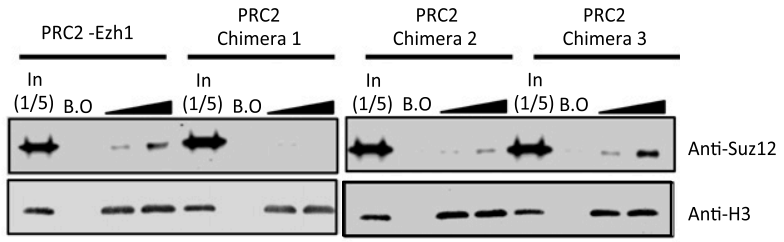

$\mathbf{F}$

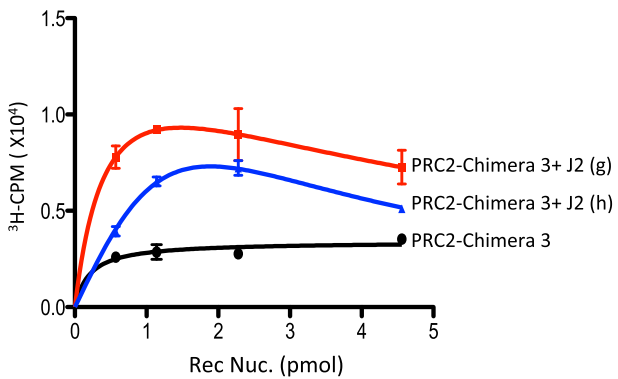

Figure 4. Minimal Ezh1 regions regulating nucleosome binding. (A) Schematic representations of Ezh1, Ezh2, and Ezh1/Ezh2 chimera (1-3) comprising the following respective amino acids: (1) Ezh1 amino acids 1-132 and Ezh2 amino acids 129-746, (2) Ezh1 amino acids 1-274 and Ezh2 amino acids 259-746, and (3) Ezh1 amino acids 1-493 and Ezh2 amino acids 490-746. Previously characterized Eed or Suz12-binding regions are shown in yellow or blue, respectively, and the SET domain is shown in red. (B) Coomassie blue staining of the Flag tag affinity-purified PRC2 complex containing different Ezh1/Ezh2 chimera from SF9 cells, as indicated. (C) Western blot analysis of increasing amounts of PRC2-Ezh1 or PRC2 comprising the Ezh1/Ezh2 chimera indicated using the antibodies shown at the right. (D) Nucleosome-binding assays using biotin mononucleosomes with the PRC2 complexes indicated. (E) HMT assay performed with increasing amounts of recombinant nucleosomes in the presence of the PRC2 complexes indicated. $(F)$ HMT assay performed with increasing amounts of recombinant nucleosomes using PRC2-Chimera 3 in the absence or presence of Jarid2 fragment $g$ or h.

loci, suggesting that Jarid2 is not required for PRC2 recruitment in myoblasts.

To determine whether, in the natural absence of Jarid2, Ezh1 now takes on a prominent role in PRC2 binding to chromatin, we performed ChIP followed by deep sequencing (ChIP-seq) for Ezh1 and Ezh2 using C2C12 cells with either Ezh1 or Ezh2 knockdown (Fig. 5D-H). Interestingly, Ezh1 binding was significantly elevated upon Ezh2 knockdown (Fig. 5F; Supplemental Fig. 4A), consistent with the elevated Ezh1 levels obtained under these conditions (Fig. 5D), suggesting that the artificial depletion of Ezh2 leads to a compensatory overexpression of Ezh1. Interestingly and importantly, this compensatory up-regulation of Ezh1 is observed in the absence of Jarid2 (Fig. 5D) but not in its presence (Fig. 5E) and is consistent with our hypothesis that the nucleosome- 
A

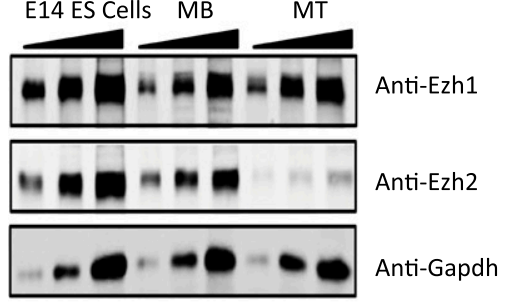

B

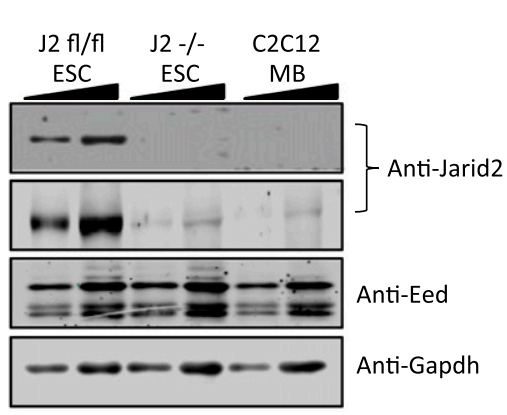

C

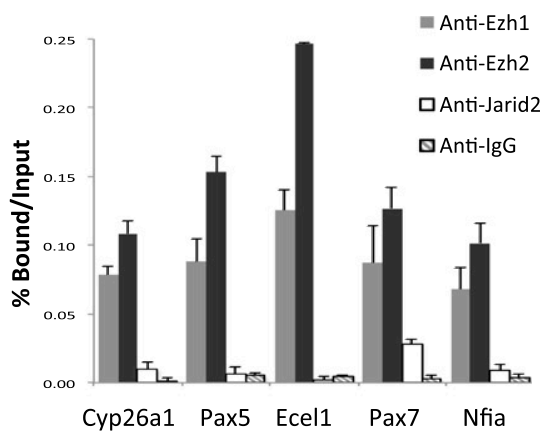

D

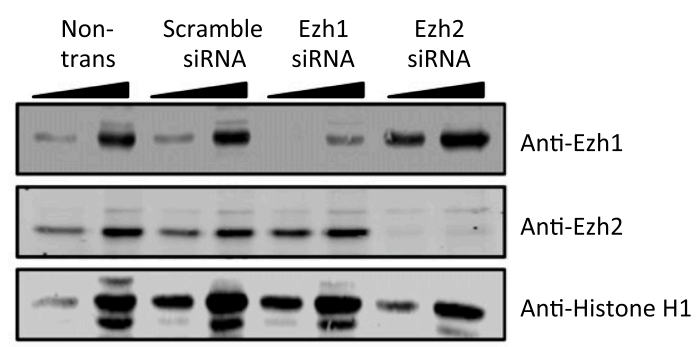

F

H

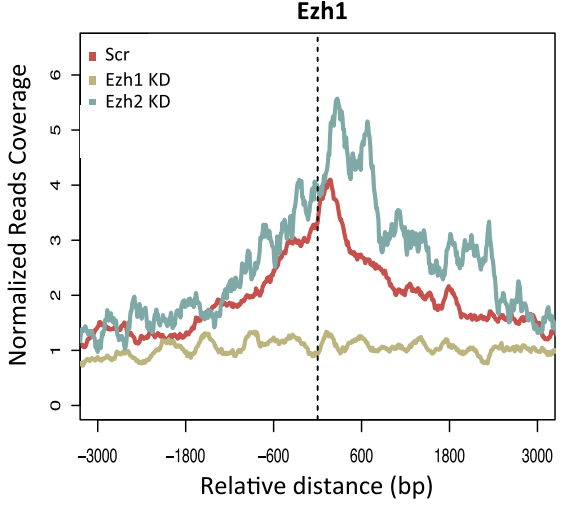

E

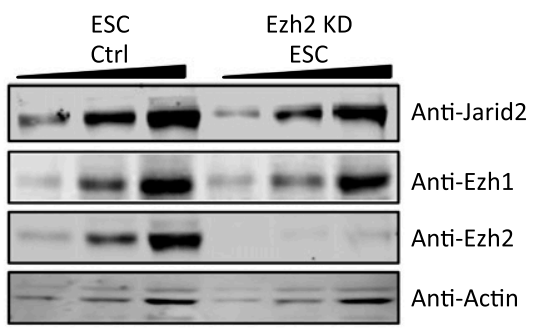

G

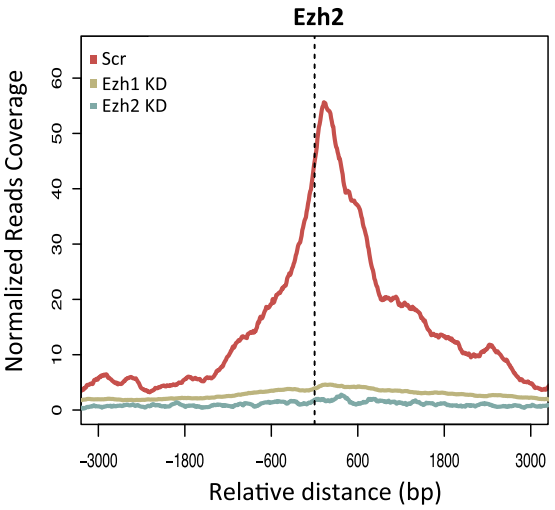

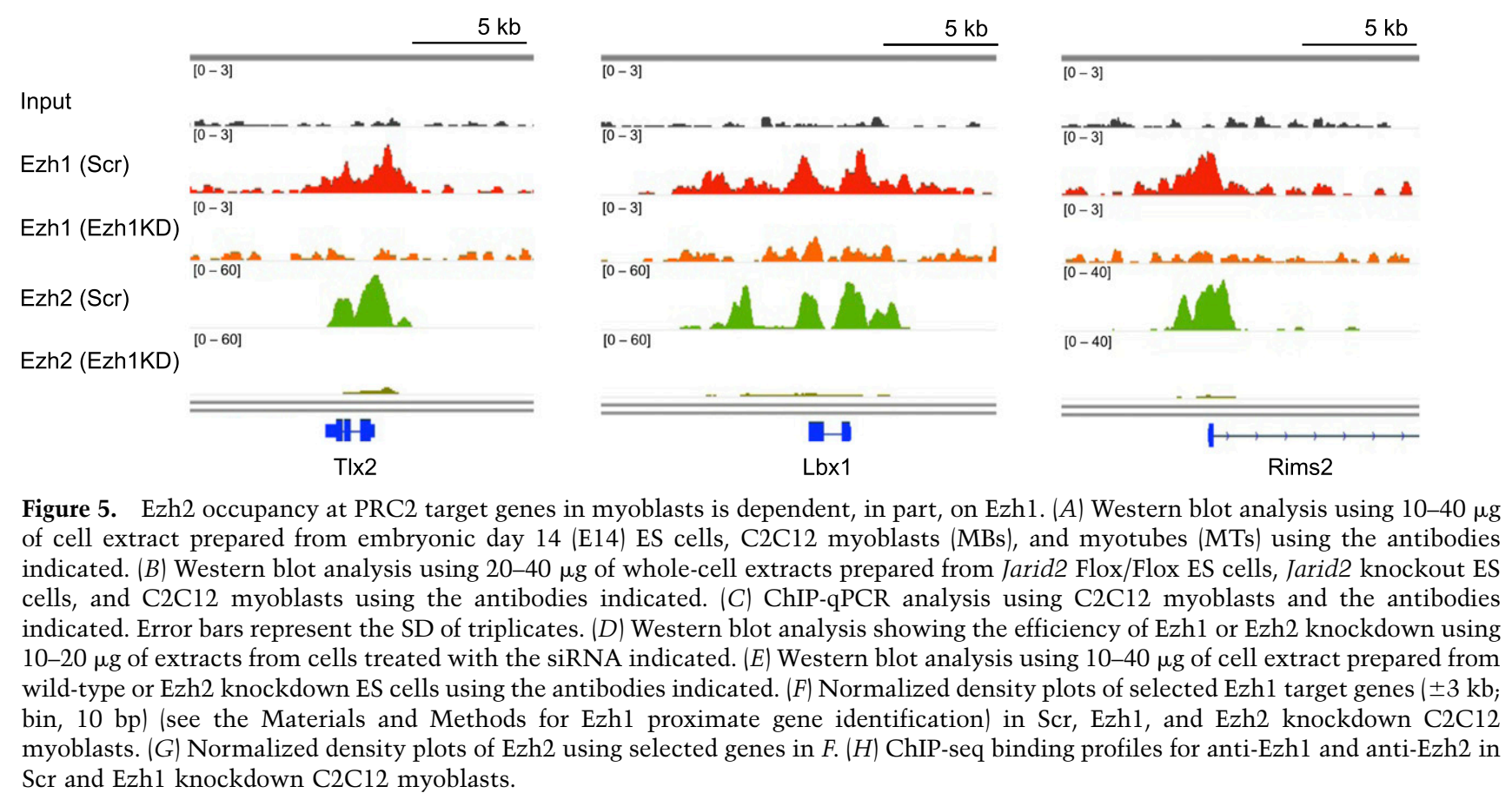


binding activity of Ezh1, at least in some contexts, can serve the same function as that of Jarid2. On the other hand, while Ezh1 knockdown was ineffectual with respect to Ezh2 protein levels (Fig. 5D), the levels of Ezh2 bound to PRC2 targets in C2C12 cells were markedly decreased (Fig. 5G,H; Supplemental Fig. 4),. We validated these ChIP-seq results using ChIP-qPCR analysis for Ezh1 and Ezh2 on numerous PRC2 targets in Ezh1 or Ezh2 knockdown C2C12 cells (Fig. 6A,B, respectively). The results indicate that Ezh1 could indeed compensate for

\section{A}

\section{Anti-Ezh1}

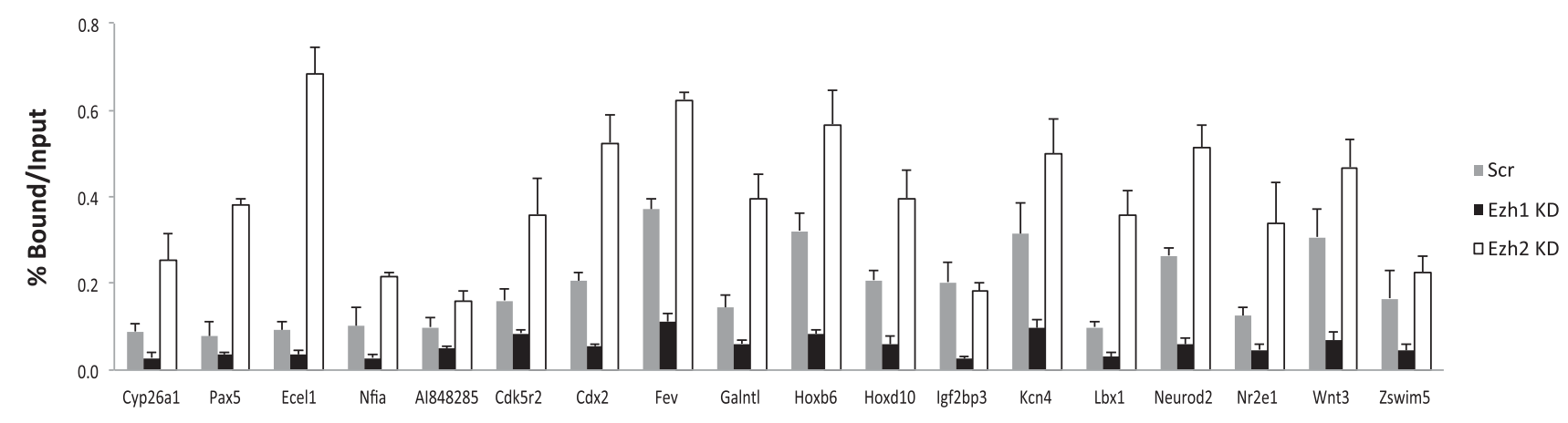

B

Anti-Ezh2

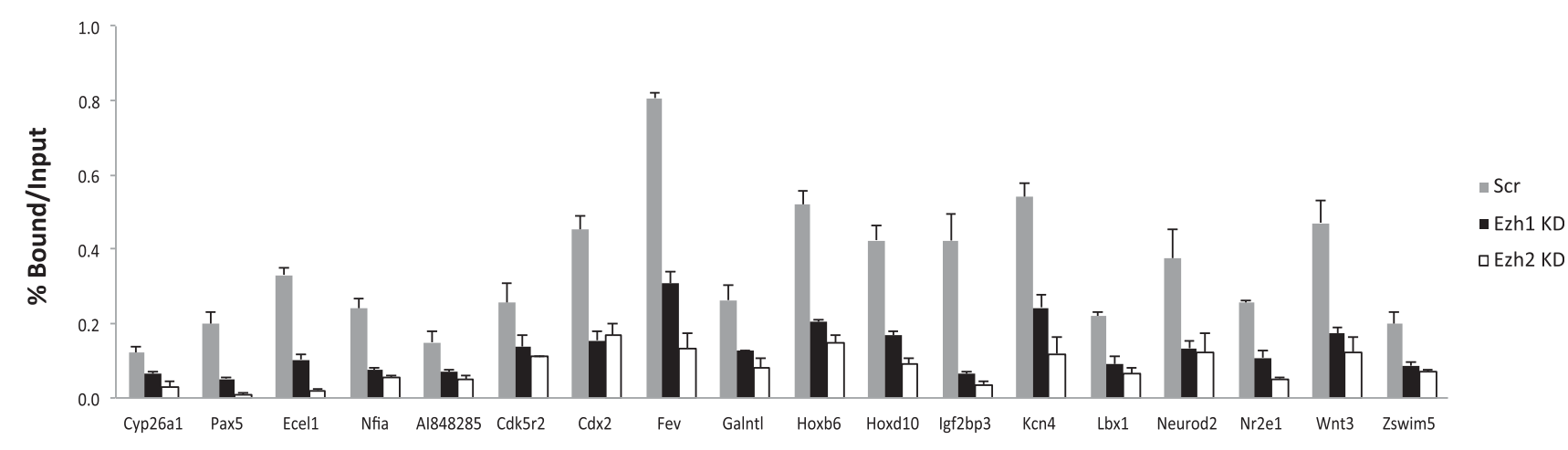

C

Anti-H3

Anti-H3K27me3
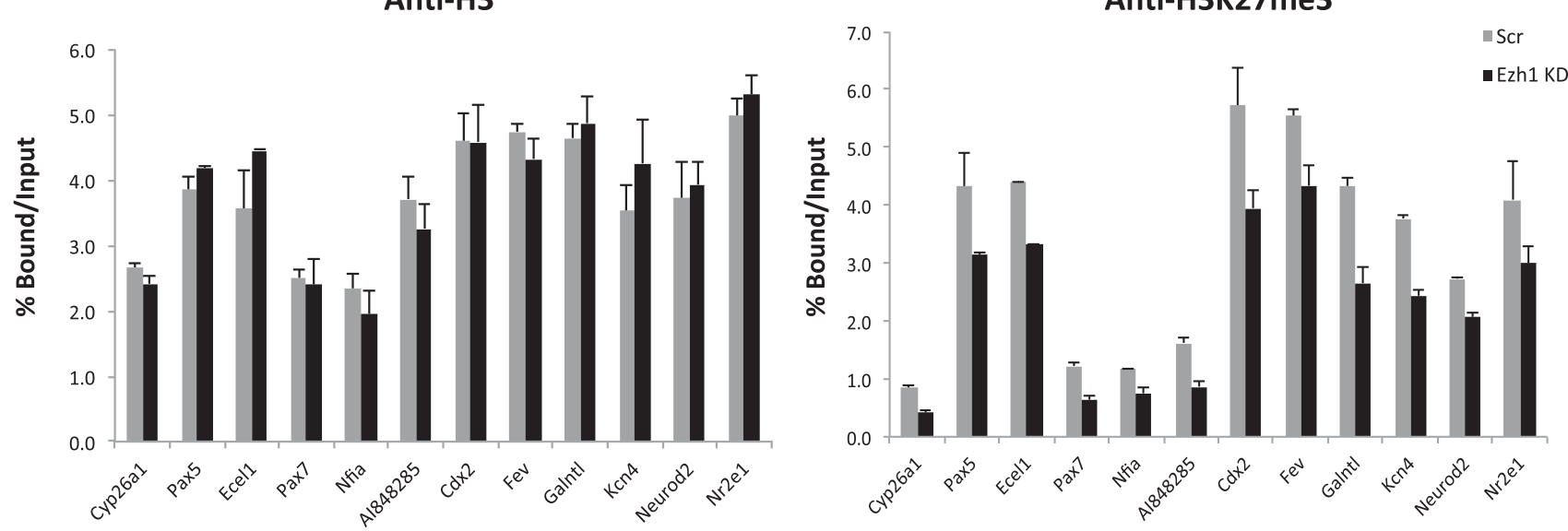

Figure 6. Decreased H3K27me3 levels on PRC2 targets upon Ezh1 knockdown. (A) ChIP-qPCR analysis for anti-Ezh1 using Ezh1 or Ezh2 knockdown C2C12 myoblasts (MBs). (B) ChIP-qPCR analysis as in A using Ezh2 antibody. (C) ChIP-qPCR analysis for anti-H3 (left panel) or anti-H3K27me3 (right panel) using Scr or Ezh1 knockdown C2C12. Error bars represent the SD of triplicates. 
the absence of Jarid2 (Fig. 6A) and play a critical role for Ezh2 binding on PRC2 targets in C2C12 (Fig. 6B). This finding was not limited to the myoblast model; Jarid2 is also undetectable in immortalized mouse embryonic fibroblast (iMEF) and NIT3T3 cells, and these cells exhibited similar profiles upon Ezh1 or Ezh2 knockdown (Supplemental Fig. 5). As a consequence of Ezh1 knockdown in C2C12 cells, H3K27me3 levels on PRC2 targets were decreased (Fig. 6C), but this was not observed in the case of Ezh2 knockdown (data not shown). This contrast highlights that PRC2-Ezh1 is capable of sustaining H3K27me3 levels in the absence of Jarid2 and Ezh2, while PRC2-Ezh2 is incapable of doing so in the absence of Jarid2 and Ezh1 (see the Discussion).

Thus, although the Ezh2 subunit of PRC2 is capable of robust HMT activity, PRC2 effectiveness requires the nucleosome-binding activity associated with either
Jarid2, as shown here, or Ezh1, also shown here. The absence of Jarid2 in differentiated cells is not detrimental to PRC2 effectiveness as long as Ezh1 is present.

\section{Discussion}

Our analysis of the PRC2 HMT activity as it relates to its associated factor, Jarid2, identified three domains in Jarid2 that are required to mediate PRC2 stimulation: a domain (residues 119-229) required for stimulation of catalysis, an Ezh2-binding domain (residues 229-349), and a nucleosome-binding domain (residues 350-450) (Fig. 7A). Importantly, the latter is a distinguishing determinant in Jarid2 modulation of PRC2 activity that is dependent on the Ezh homolog that it comprises.

Before being identified as a PRC2-interacting protein and as the founding member of the Jumonji family of

A

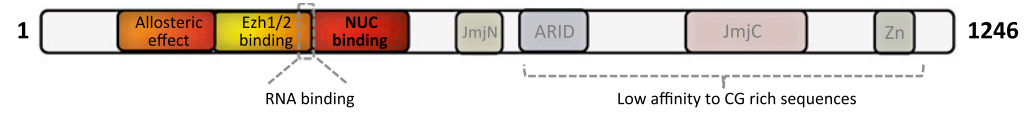

B

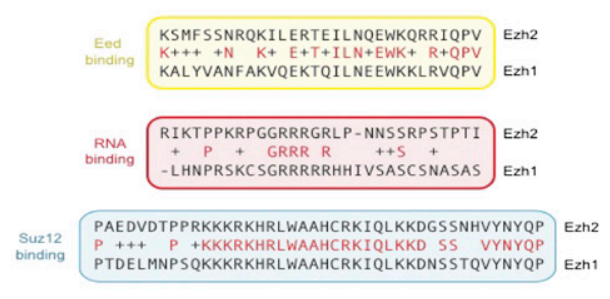

C

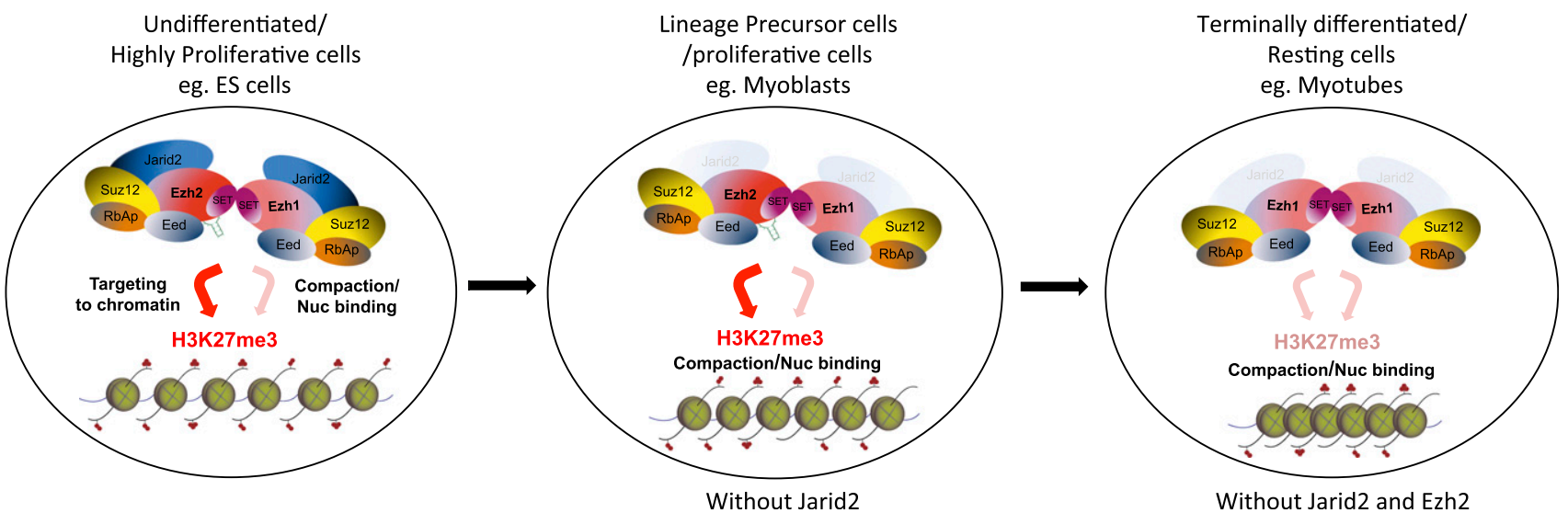

Figure 7. (A) Schematic representation of Jarid2 indicating three functional domains located within the $\mathrm{N}$ terminus, as identified in this study. The RNA-binding domain is described by Kaneko et al. (in press). (B) Comparison of amino acid sequences of different domains present in Ezh1 and/or Ezh2. The conservation between the Eed-, RNA-, and Suz12-binding domains is shown. Note the low degree of conservation in the RNA-binding domain, consistent with the lack of Ezh1 RNA-binding activity. $(C)$ Schematic model of the establishment and maintenance of H3K27me by PRC2. (Left) A dividing cell contains PRC2-Ezh2, PRC2-Ezh1, and Jarid2. PRC2-Ezh2 contains robust H3K27me3 activity, whereas PRC2-Ezh1 is less active in catalyzing H3K27me3 but can compact chromatin. Jarid2 and noncoding RNA can recruit PRC2-Ezh2 to its targets. (Middle) A lineage precursor cell lacks Jarid2; however, PRC2-Ezh2 can bind to chromatin through dimerization with PRC2-Ezh1. (Right) A differentiated cell lacks Ezh2 and Jarid2 such that the levels of H3K27me3 are maintained by PRC2-Ezh1 through its ability to bind nucleosomes in general and the allosteric stimulation of its HMT activity upon binding of its Eed subunit to pre-existing H3K27me3. 
proteins, Jarid2 had already been reported to function as a transcriptional repressor especially important for heart development (Lee et al. 2000; Kim et al. 2003) and cell cycle regulation (Jung et al. 2005). Interestingly, the Jarid2 $\mathrm{C}$ terminus (which includes its Arid and zinc finger domains) can bind directly to DNA with low affinity but preferentially toward CpG-rich motifs (Peng et al. 2009; Li et al. 2010). This feature was particularly interesting, since the genome-wide localization of PRC2 correlated with unmethylated CpG-rich regions (Bernstein et al. 2006), and, most importantly, ectopic incorporation of CpG-rich domains into ES cells, which contain high levels of Jarid2, was sufficient for PRC2 recruitment (Mendenhall et al. 2010). However, since Jarid2 exhibited only low affinity toward sequences rich in $\mathrm{CpG}$, this property does not likely account for its full contribution to PRC2 recruitment. Indeed, we postulated that PRC2 recruitment to target sites is dependent on multiple, lowaffinity interactions with chromatin (Margueron and Reinberg 2011). Our results showing that Jarid2 can also contact nucleosomes provide another mechanism accounting for the increased accessibility of Jarid2-PRC2 to chromatin and may also explain their reported interdependent recruitment to target genes in actively dividing cells (Peng et al. 2009; Landeira et al. 2010; Li et al. 2010; Pasini et al. 2010; Herz et al. 2012).

The catalytic subunit of PRC2 is encoded by the Ezh gene that was duplicated in the case of mammals, giving rise to Ezh1 and Ezh2, which appear to associate independently with the other PRC2 subunits. However, the existence of PRC2 species containing both Ezh1 and Ezh2 indicates PRC2 dimer formation (Margueron et al. 2008). Although PRC2-Ezh1 has been reported to exhibit HMT activity to an extent similar to that of PRC2-Ezh2 (Shen et al. 2008), the highly purified PRC2-Ezh1 complex has considerably reduced specific activity in catalyzing H3K27me2-3 relative to PRC2-Ezh2 (Margueron et al. 2008; this study). In addition, we observed that, similar to the case of PRC2-Ezh2 (Margueron et al. 2009), PRC2Ezh1 activity is stimulated by Jarid2, suggesting that Jarid2 regulates PRC2 activity through at least two independent mechanisms: binding to nucleosomes and independently stimulating catalysis, possibly via allosteric modulation.

Previous reports suggested that Ezh1 and Ezh2 are essentially redundant (Shen et al. 2008; Ezhkova et al. 2009). However, a recent study demonstrated that Ezh1 deletion induced a significant loss of adult hematopoietic stem cells (Hidalgo et al. 2012) due to defects in selfrenewal and quiescence, which are not observed upon Ezh2 deletion (Mochizuki-Kashio et al. 2011). The redundancy hypothesis is also challenged by other findings: While Ezh1 and Ezh2 share common target genes, their patterns of expression are markedly different (Laible et al. 1997; Margueron et al. 2008); our previous characterization of an Ezh2 domain required for binding to noncoding RNA is not conserved within Ezh1 (Fig. 7B; Kaneko et al. 2010); and PRC2-Ezh1 and PRC2-Ezh2 display distinct biochemical properties, with Ezh2 exhibiting robust HMT activity, in contrast to Ezh1 (Margueron et al. 2008), and
Ezh1 exhibiting binding to nucleosomes (this study) consistent with its role in chromatin compaction (Margueron et al. 2008), in contrast to Ezh2. Importantly, this redundancy hypothesis is challenged by genetic studies in mice demonstrating that deletion of the Ezh2 gene results in lethality (O'Carroll et al. 2001), whereas deletion of Ezh1 has no effect on viability (Ezhkova et al. 2011; A. Tarakhovsky, pers. comm.). Finally, as reported here, Ezh1 expression in the myoblast and fibroblast cell models modulates PRC2-Ezh2 enrichment at chromatin, whereas the reverse was not true. Together, these observations argue against the interchangeability of PRC2Ezh1 and PRC2-Ezh2 functions.

These disparities between the Ezh1 and Ezh2 homologs are the basis of our proposed model (Fig. 7C) in which PRC2-Ezh2, with its inherent robust HMT activity, can access chromatin and establish the repressive H3K27me3 modification at its target loci in cells containing high levels of Jarid2 expression; e.g., ES cells. This mechanism requires minimally the RNA-binding domain of Ezh2, which, as we (Kaneko et al. 2010) and others (Rinn et al. 2007; Zhao et al. 2008, 2010) have speculated, likely confers specificity in gene targeting, and Jarid2, which facilitates PRC2-Ezh2 access to nucleosomes in addition to other interactions between PRC2 and chromatin (Margueron and Reinberg 2011). In more committed, Jarid2-deficient cells, such as C2C12, iMEF, and NIH3T3, PRC2-Ezh1 is the determining factor that promotes PRC2-Ezh2 access to chromatin. In resting cells, where both Jarid2 and Ezh2 are absent, the repression established by PRC2-Ezh2 during the process of differentiation is then maintained by PRC2-Ezh1. This model shows that PRC2-Ezh1 can bind to nucleosomes in the absence of Jarid2 (Fig. 3) and that the H3K27me3 mark established during early differentiation steps is recognized and propagated by the PRC2-Ezh1 complex (Supplemental Fig. 3). Indeed, the Ezh1-containing complex exhibits both of these properties, as demonstrated in the present study. A remaining question is why cells that have initiated lineage commitment would retain Ezh2. A likely explanation is that these cells are not terminally differentiated and undergo DNA replication and mitosis, and therefore an efficient mechanism to replenish H3K27me3 diluted during DNA replication must be in place.

Further evidence in support of the critical role for Ezh1 in the transition from pluripotency to lineage commitment is found in a study that showed how myotube differentiation is impaired upon Ezh1 knockdown (Stojic et al. 2011). This impairment is in accordance with our model, as the PRC2-Ezh1 complex predominates in terminally differentiated cells (being responsible for maintaining the repressed state imposed by the presence of H3K27me3) through its chromatin compaction function and low-level HMT activity. This Ezh1-specific role is consistent with its gain of function relative to Ezh2 with respect to nucleosome binding. This model expands on the known differences between mammalian and Drosophila PRC2, with two Ezh species being necessary to account for the far greater complexity inherent in the mammalian system. 


\section{Materials and methods}

\section{Cloning}

His-Jarid2 fragments were cloned by PCR into PET102 TOPO plasmid (Invitrogen) for bacterial expression.

\section{Antibodies}

Antibodies against Ezh1, Ezh2, Suz12, Eed, and Jarid2 were produced in the laboratory. Other commercial antibodies-RbAp46 (Abcam, catalog no. ab488), H1 (Santa Cruz Biotechnology, catalog no. sc10806), H3K27me3 (Millipore, catalog no. 07-449), H3 (Abcam, catalog no. ab1791), GADPH (GeneTex, catalog no. GTX627408), Actin (Abcam, catalog no. ab3280), His tag (Genscript, catalog no. A00186), Flag (Sigma, catalog no. F3165), and GST (Santa Cruz Biotechnology, catalog no. sc33613)—were purchased from the companies indicated.

\section{Baculovirus}

Baculovirus expression plasmids for Flag-His-tagged Ezh1, Flag-Histagged or His-tagged Ezh2, His-tagged Eed, His-tagged Suz12, and untagged RbAp48 were used as previously described (Margueron et al. 2008). Baculovirus expression plasmids for the Ezh1/Ezh2 series of chimera were cloned into pacHLTc. Aebp2 baculovirus was kindly provided by Dr. Y. Zhang. Recombinant PRC2-Ezh1, PRC2-Ezh2, and PRC2-Ezh1/Ezh2 chimeras or Aebp2 were produced in SF9 cells grown in SF-900 III SFM (Invitrogen). After $72 \mathrm{~h}$ of infection, SF9 cells were resuspended in BC350 $(25 \mathrm{mM}$ Tris- $\mathrm{HCl}$ at $\mathrm{pH} 7.9,0.2 \mathrm{mM}$ EDTA, $350 \mathrm{mM} \mathrm{KCl}, 10 \%$ glycerol) with $0.1 \%$ NP40 and $1 \mathrm{mM}$ PMSF and lysed by sonication (Fisher Sonic Dismembrator model 100) at a maximum output power of $\sim 12 \mathrm{~W}$ for $30 \mathrm{sec}$. The lysate was incubated for $3 \mathrm{~h}$ with Flag-M2 agarose beads (Sigma). After washing with the same buffer, PRC2 was eluted with $0.2 \mathrm{mg} / \mathrm{mL}$ Flag peptide in $\mathrm{BC} 100(25 \mathrm{mM}$ Tris$\mathrm{HCl}$ at $\mathrm{pH} 7.9,0.2 \mathrm{mM}$ EDTA, $100 \mathrm{mM} \mathrm{KCl}, 10 \%$ glycerol) with $1 \mathrm{mM}$ PMSF.

\section{Bacterial recombinant proteins}

His-Jarid2 N-terminal fragments were expressed in BL21 (DE3) cells upon IPTG induction. The cells were resuspended with Hislysis buffer (10 mM HEPES- $\mathrm{HCl}$ at $\mathrm{pH} 7.5,350 \mathrm{mM} \mathrm{NaCl}, 0.1 \%$ NP40, 15\% glycerol, $1 \mathrm{mM}$ DTT, $1 \mathrm{mM}$ PMSF) containing $15 \mathrm{mM}$ imidazole and lysed by sonication (Fisher Sonic Dismembrator model 100) at a maximum output power of $\sim 16 \mathrm{~W}$ for $2 \mathrm{~min}$. The lysate was incubated with Ni-NTA beads (Qiagen) for $2 \mathrm{~h}$. After washing with His-lysis buffer containing $30 \mathrm{mM}$ imidazole, His-recombinant proteins were eluted with increasing concentrations $(50,100,150$, and $250 \mathrm{mM})$ of imidazole in His-lysis buffer.

\section{Nucleosome reconstitution}

Recombinant histones were generated as described previously (Luger et al. 1999; Simon et al. 2007; Margueron et al. 2009). Briefly, each core histone was expressed in BL21 (DE3) pLYS cells, extracted from inclusion bodies, and purified by sequential anion and cation chromatography. For refolding recombinant octamers, equal amounts of histones were mixed and dialyzed into refolding buffer $(10 \mathrm{mM}$ Tris- $\mathrm{HCl}$ at $\mathrm{pH} 7.5,2 \mathrm{M} \mathrm{NaCl}$, $1 \mathrm{mM}$ EDTA, $5 \mathrm{mM} \beta$-mercaptoethanol). Octamers were further purified by size exclusion chromatography on a 24-mL Superdex 200 column (Amersham Biosciences) in refolding buffer. Recombinant mono- and oligo-nucleosomes were reconstituted by sequential salt dialysis of octamers and DNA fragment containing one 601-nucleosome positioning sequence or plasmid having 12 601-nucleosome positioning sequences.

\section{HMT assay}

Standard HMT assays were performed as described (Margueron et al. 2009). Briefly, the reaction was performed in a total volume of $25 \mu \mathrm{L}$ of HMT buffer (50 mM Tris- $\mathrm{HCl}$ at $\mathrm{pH} 8.5,5 \mathrm{mM} \mathrm{MgCl}_{2}$, $4 \mathrm{mM}$ DTT) with ${ }^{3} \mathrm{H}$-labeled or cold SAM, substrates (recombinant nucleosomes), and PRC2 under the following conditions. For most reactions scored by scintillation counting, if not indicated otherwise, the conditions were as follows: $0.67 \mathrm{pmol}$ of PRC2, $12.5 \mu \mathrm{M}$ SAM $\left({ }^{3} \mathrm{H}\right.$ SAM/cold SAM at a 1:45 ratio) and $2.28 \mathrm{pmol}$ of recombinant nucleosomes with $1 \mathrm{pmol}$ of Jarid2, 4 pmol of Aebp2, or $80 \mu \mathrm{M} \mathrm{H} 3 \mathrm{~K} 27 \mathrm{me} 3$ peptide. The reaction mixture was incubated for $15 \mathrm{~min}$ at $30^{\circ} \mathrm{C}$ and analyzed by scintillation counting after SDS-PAGE.

\section{Flag pull-down assay}

Mammalian Flag-tagged Ezh1 or Ezh2 prepared from SF9 cells was incubated with different recombinant His-Jarid2 fragments and Flag-M2 agarose beads (Sigma) in BC350 with $0.05 \%$ NP40, $1 \mathrm{mM} \mathrm{DTT}$, and $1 \mathrm{mM}$ PMSF for $2 \mathrm{~h}$ at $4^{\circ} \mathrm{C}$. After extensive washing with the same buffer, beads were boiled with SDS buffer and subjected to Coomassie blue staining.

\section{Nucleosome-binding assay}

Biotinylated (biotin) mono- or oligo-nucleosomes (18.24 pmol) were incubated with $6.7 \mathrm{pmol}$ of PRC2 and $20 \mu \mathrm{L}$ of streptavidin agarose (Millipore) in the presence of $40 \mathrm{pmol}$ of Aebp2 and/or $10 \mathrm{pmol}$ of Jarid2. The assay was performed in binding buffer ( $50 \mathrm{mM}$ Tris- $\mathrm{HCl}$ at $\mathrm{pH} 7.9,100 \mathrm{mM} \mathrm{KCl}, 0.05 \% \mathrm{NP} 40$ ) for $2 \mathrm{~h}$ at $4^{\circ} \mathrm{C}$. After extensive washing, beads were boiled with SDS buffer and subjected to Western blot using anti-Ezh2, anti-His tag, or anti-H3 antibody. After incubation with either the secondary IRDye Alexa Fluor 680 goat anti-mouse IgG (Molecular Probes) or IRDye $800 \mathrm{CW}$ donkey anti-rabbit IgG (Rockland), the membranes were visualized with the Odyssey infrared imaging system (Li-Cor).

\section{Sucrose gradient sedimentation assay}

Sucrose gradients were performed using a gradient maker (Biocomp) as described (Margueron et al. 2008). Briefly, $18.24 \mathrm{pmol}$ of recombinant nucleosomes or DNA was incubated with $80 \mathrm{pmol}$ of Jarid2 fragment or AEBP2 in HEB buffer ( $25 \mathrm{mM}$ HEPES-HCl at $\mathrm{pH} 7.5,40 \mathrm{mM} \mathrm{KCl}, 0.2 \mathrm{mM}$ EDTA, $1 \mathrm{mM} \mathrm{DTT}$ ) for $1 \mathrm{~h}$ at room temperature and then loaded onto a $4.5-\mathrm{mL} 10 \%-30 \%$ sucrose gradient. The sample was centrifuged at $22,000 \mathrm{rpm}$ for $16 \mathrm{~h}$ in a Beckman SW60Ti rotor. Each $250-\mu \mathrm{L}$ fraction of the resulting gradient was loaded with SDS on a $0.8 \%$ agarose gel.

\section{Gel mobility shift assay}

Mononucleosomes and Jarid2 proteins were incubated in $10 \mathrm{mM}$ HEPES-HCl (pH 7.9), 50 mM KCl, 0.02 mM EDTA, 10\% glycerol, $1 \mathrm{mM}$ DTT, $0.05 \% \mathrm{NP} 40,0.4 \mu \mathrm{g}$ of BSA, and $25 \mu \mathrm{g} / \mathrm{mL}$ poly $(\mathrm{dA})-$ poly (dT) in a total volume of $10 \mu \mathrm{L}$ for $30 \mathrm{~min}$ at $4^{\circ} \mathrm{C}$. The products of the reaction were analyzed by $4 \%$ native polyacrylamide gel electrophoresis (19:1) in 1× TGE buffer (25 mM Tris, $190 \mathrm{mM}$ glycine, $1 \mathrm{mM}$ EDTA at $\mathrm{pH}$ 8.3) followed by SYBR Gold (Molecular Probes) staining. 


\section{Cell culture and siRNA transfection}

Mouse ES cell line E14Tg2A.4, Ezh2 knockdown, Jarid2 Flox/ Flox, and Jarid2 knockout mouse ES cells were cultured on gelatin-coated dishes in Dulbecco's modified Eagle's medium (DMEM) supplemented with 15\% FBS (Hyclone), 100 mM MEM nonessential amino acids (Sigma), 0.1 mM 2-mercaptoethanol (Sigma), $1 \mathrm{mM}$ L-glutamine (Invitrogen), and $\sim 100 \mathrm{U} / \mathrm{mL}$ leukemia inhibitory factor (LIF) (Chemicon). The C2C12 murine myoblast and iMEF cells were cultured in DMEM containing $10 \%$ FBS. NIH3T3 cells were cultured in DMEM with $10 \%$ bovine serum (Sigma). To induce differentiation, C2C12 myoblasts were grown to confluence and cultured in DMEM supplemented with $2 \%$ horse serum. After $4 \mathrm{~d}$ of differentiation, myotubes were harvested from undifferentiated cells using diluted trypsin as described (Blais et al. 2007). siRNA transfections were performed using Lipofectamine RNAiMax (Invitrogen) according to the manufacturer's instructions. Cells were harvested $1 \mathrm{wk}$ after serial transfections for Western blot, ChIP-seq, or ChIP-qPCR. AllStars negative control siRNA (Qiagen) was used for scramble siRNA. siRNA sequences for Ezh1 and Ezh2 were as follows: siRNA for Ezh1, UGAAGGAGAGGUAUCGAGA; and siRNA for Ezh2, GGUAAAUGCUCUUGGUCAA.

\section{ChIP-qPCR}

ChIP was performed basically as described previously (Margueron et al. 2008; Li et al. 2010). qPCR was carried out in triplicate using SYBR Green reagent (Roche) in the MxPro machine (Stratagene). At least three independent experiments were performed for each ChIP assay. Primer sequences were as described in Supplemental Table 1.

\section{Library construction for ChIP-seq}

Libraries for ChIP-seq were prepared according to manufacturer's instructions (Illumina) and as described (Gao et al. 2012). Briefly, immunoprecipitated DNA was end-repaired using End-It repair kit (Epicenter), A-tailed using Klenow exo (New England Biolabs), and ligated to custom barcode adapters with T4 ligase (Enzymatics). Fragments of $300 \pm 50$ base pairs (bp) were sizeselected and subjected to ligation-mediated PCR amplification (LM-PCR) using Phusion DNA polymerase (New England Biolabs). After quantification, libraries were sequenced on an Illumina HiSeq2000. Barcoding was used to sequence more than one sample per lane.

\section{ChIP-seq computation analysis}

Sequencing read mapping and preprocessing All raw sequencing reads were mapped to the mouse genome (NCBI37/ $\mathrm{mm}$ ) ) by using Bowtie aligner (0.12.9) with v2 and $\mathrm{m} 1$ parameters. The mapped reads were subsequently sorted with SAMtools (0.1.19) before further analysis. To generate the visualization files for Integrative Genomics Viewer (IGV) genome browser, each individual sorted BAM file was converted to a TDF file by using IGV tools, in which each read was extended by $250 \mathrm{bp}$, which is approximately the DNA fragment length. The reads were normalized with the IGV tools. All sequencing data have been deposited to the Gene Expression Omnibus under accession number SRP032543.

Identification of enriched regions (peak calling) In general, the positive binding regions of Ezh1 and Ezh2 were called by using MACS1.4.2c package with the default parameter and default cutoff. To define the Ezh1 proximate genes, we selected genes that have Ezh1-binding peaks within $3 \mathrm{~kb}$ of a transcription start site (TSS).
Visualization of read distribution of peak regions or a particular genome area such as a TSS region The read coverage on a single base was calculated and normalized by the total number of mapped reads such that each sample contains 10 million reads. To generate the histogram data table for visualizing average read coverage in a particular region, the normalized read coverage was summarized and calculated in 10-bp sliding windows.

\section{Acknowledgments}

We thank Y. Yang and Dr. B. Dynlacht for providing C2C12 cells; Dr. S. Orkin for Jarid2 ${ }^{\mathrm{fl} / \mathrm{fl}}$ and Jarid2 knockout ES cells; Dr. S. Kaneko, Dr. G. Li, and Dr. S. Tu for reagents and helpful discussions; Dr. W-W. Tee and Dr. R. Bonasio for valuable comments on the manuscript; and Dr. S. Gamblin for great advice. We are also grateful to Dr. L. Vales for insightful discussion and comments on the manuscript. This work was supported by a grant from the National Institutes of Health (GM-64844) and the Howard Hughes Medical Institute to D.R.

\section{References}

Bernstein BE, Mikkelsen TS, Xie X, Kamal M, Huebert DJ, Cuff J, Fry B, Meissner A, Wernig M, Plath K, et al. 2006. A bivalent chromatin structure marks key developmental genes in embryonic stem cells. Cell 125: 315-326.

Blais A, van Oevelen CJ, Margueron R, Acosta-Alvear D, Dynlacht BD. 2007. Retinoblastoma tumor suppressor protein-dependent methylation of histone H3 lysine 27 is associated with irreversible cell cycle exit. J Cell Biol 179: 1399-1412.

Brown JL, Mucci D, Whiteley M, Dirksen ML, Kassis JA. 1998. The Drosophila Polycomb group gene pleiohomeotic encodes a DNA binding protein with homology to the transcription factor YY1. Mol Cell 1: 1057-1064.

Cao R, Zhang Y. 2004. SUZ12 is required for both the histone methyltransferase activity and the silencing function of the EED-EZH2 complex. Mol Cell 15: 57-67.

Cao R, Wang L, Wang H, Xia L, Erdjument-Bromage H, Tempst P, Jones RS, Zhang Y. 2002. Role of histone H3 lysine 27 methylation in Polycomb-group silencing. Science 298: 10391043.

Christensen I, Agger K, Cloos PA, Pasini D, Rose S, Sennels L, Rappsilber J, Hansen KH, Salcini AE, Helin K. 2007. RBP2 belongs to a family of demethylases, specific for tri-and dimethylated lysine 4 on histone 3. Cell 128: 1063-1076.

Ezhkova E, Pasolli HA, Parker JS, Stokes N, Su IH, Hannon G, Tarakhovsky A, Fuchs E. 2009. Ezh2 orchestrates gene expression for the stepwise differentiation of tissue-specific stem cells. Cell 136: 1122-1135.

Ezhkova E, Lien WH, Stokes N, Pasolli HA, Silva JM, Fuchs E. 2011. EZH1 and EZH2 cogovern histone H3K27 trimethylation and are essential for hair follicle homeostasis and wound repair. Genes Dev 25: 485-498.

Gao Z, Zhang J, Bonasio R, Strino F, Sawai A, Parisi F, Kluger Y, Reinberg D. 2012. PCGF homologs, CBX proteins, and RYBP define functionally distinct PRC1 family complexes. Mol Cell 45: 344-356.

Herz HM, Mohan M, Garrett AS, Miller C, Casto D, Zhang Y, Seidel C, Haug IS, Florens L, Washburn MP, et al. 2012. Polycomb repressive complex 2-dependent and -independent functions of Jarid2 in transcriptional regulation in Drosophila. Mol Cell Biol 32: 1683-1693.

Hidalgo I, Herrera-Merchan A, Ligos JM, Carramolino L, Nunez J, Martinez F, Dominguez O, Torres M, Gonzalez S. 2012. 
Ezh1 is required for hematopoietic stem cell maintenance and prevents senescence-like cell cycle arrest. Cell Stem Cell 11: 649-662.

Jacobs JJ, van Lohuizen M. 1999. Cellular memory of transcriptional states by Polycomb-group proteins. Semin Cell Dev Biol 10: 227-235.

Jung J, Mysliwiec MR, Lee Y. 2005. Roles of JUMONJI in mouse embryonic development. Dev Dyn 232: 21-32.

Kaneko S, Li G, Son J, Xu CF, Margueron R, Neubert TA, Reinberg D. 2010. Phosphorylation of the PRC2 component Ezh2 is cell cycle-regulated and up-regulates its binding to ncRNA. Genes Dev 24: 2615-2620.

Kaneko S, Bonasio R, Saldaña-Meyer R, Yoshida T, Son J, Nishino K, Umezawa A, Reinberg D. Interactions between JARID2 and noncoding RNAs regulate PRC2 recruitment to chromatin. Mol Cell (in press).

Kim TG, Kraus JC, Chen J, Lee Y. 2003. JUMONJI, a critical factor for cardiac development, functions as a transcriptional repressor. I Biol Chem 278: 42247-42255.

Kim H, Kang K, Kim J. 2009. AEBP2 as a potential targeting protein for Polycomb repression complex PRC2. Nucleic Acids Res 37: 2940-2950.

Klose RJ, Yamane K, Bae Y, Zhang D, Erdjument-Bromage H, Tempst P, Wong I, Zhang Y. 2006. The transcriptional repressor JHDM3A demethylates trimethyl histone $\mathrm{H} 3 \mathrm{ly}$ sine 9 and lysine 36. Nature 442: 312-316.

Kuzmichev A, Nishioka K, Erdjument-Bromage H, Tempst P, Reinberg D. 2002. Histone methyltransferase activity associated with a human multiprotein complex containing the Enhancer of Zeste protein. Genes Dev 16: 2893-2905.

Laible G, Wolf A, Dorn R, Reuter G, Nislow C, Lebersorger A, Popkin D, Pillus L, Jenuwein T. 1997. Mammalian homologues of the Polycomb-group gene Enhancer of zeste mediate gene silencing in Drosophila heterochromatin and at S. cerevisiae telomeres. EMBO J 16: 3219-3232.

Landeira D, Sauer S, Poot R, Dvorkina M, Mazzarella L, Jorgensen HF, Pereira CF, Leleu M, Piccolo FM, Spivakov $M$, et al. 2010. Jarid2 is a PRC2 component in embryonic stem cells required for multi-lineage differentiation and recruitment of PRC1 and RNA Polymerase II to developmental regulators. Nat Cell Biol 12: 618-624.

Lee Y, Song AJ, Baker R, Micales B, Conway SI, Lyons GE. 2000. Jumonji, a nuclear protein that is necessary for normal heart development. Circ Res 86: 932-938.

Lewis EB. 1978. A gene complex controlling segmentation in Drosophila. Nature 276: 565-570.

Li G, Margueron R, Ku M, Chambon P, Bernstein BE, Reinberg D. 2010. Jarid2 and $\mathrm{PRC} 2$, partners in regulating gene expression. Genes Dev 24: 368-380.

Luger K, Rechsteiner TJ, Richmond TJ. 1999. Expression and purification of recombinant histones and nucleosome reconstitution. Methods Mol Biol 119: 1-16.

Margueron R, Reinberg D. 2011. The Polycomb complex PRC2 and its mark in life. Nature 469: 343-349.

Margueron R, Li G, Sarma K, Blais A, Zavadil J, Woodcock CL, Dynlacht BD, Reinberg D. 2008. Ezh1 and Ezh2 maintain repressive chromatin through different mechanisms. Mol Cell 32: 503-518.

Margueron R, Justin N, Ohno K, Sharpe ML, Son J, Drury WJ 3rd, Voigt P, Martin SR, Taylor WR, De Marco V, et al. 2009. Role of the polycomb protein EED in the propagation of repressive histone marks. Nature 461: 762-767.

Mendenhall EM, Koche RP, Truong T, Zhou VW, Issac B, Chi AS, Ku M, Bernstein BE. 2010. GC-rich sequence elements recruit PRC2 in mammalian ES cells. PLoS Genet 6: e1001244.
Mochizuki-Kashio M, Mishima Y, Miyagi S, Negishi M, Saraya A, Konuma T, Shinga J, Koseki H, Iwama A. 2011. Dependency on the polycomb gene Ezh2 distinguishes fetal from adult hematopoietic stem cells. Blood 118: 6553-6561.

Montgomery ND, Yee D, Chen A, Kalantry S, Chamberlain SJ, Otte AP, Magnuson T. 2005. The murine polycomb group protein Eed is required for global histone H3 lysine-27 methylation. Curr Biol 15: 942-947.

Murzina NV, Pei XY, Zhang W, Sparkes M, Vicente-Garcia J, Pratap JV, McLaughlin SH, Ben-Shahar TR, Verreault A, Luisi $\mathrm{BF}$, et al. 2008. Structural basis for the recognition of histone H4 by the histone-chaperone RbAp46. Structure 16: 10771085.

O'Carroll D, Erhardt S, Pagani M, Barton SC, Surani MA, Jenuwein T. 2001. The polycomb-group gene Ezh2 is required for early mouse development. Mol Cell Biol 21: 4330-4336.

Pasini D, Bracken AP, Jensen MR, Lazzerini Denchi E, Helin K. 2004. Suz12 is essential for mouse development and for EZH2 histone methyltransferase activity. EMBO I 23: 40614071.

Pasini D, Bracken AP, Hansen JB, Capillo M, Helin K. 2007. The polycomb group protein Suz12 is required for embryonic stem cell differentiation. Mol Cell Biol 27: 3769-3779.

Pasini D, Cloos PA, Walfridsson J, Olsson L, Bukowski JP, Johansen JV, Bak M, Tommerup N, Rappsilber J, Helin K. 2010. JARID2 regulates binding of the Polycomb repressive complex 2 to target genes in ES cells. Nature 464: 306-310.

Peng JC, Valouev A, Swigut T, Zhang J, Zhao Y, Sidow A, Wysocka J. 2009. Jarid2/Jumonji coordinates control of PRC2 enzymatic activity and target gene occupancy in pluripotent cells. Cell 139: 1290-1302.

Rinn JL, Kertesz M, Wang JK, Squazzo SL, Xu X, Brugmann SA, Goodnough LH, Helms JA, Farnham PJ, Segal E, et al. 2007. Functional demarcation of active and silent chromatin domains in human HOX loci by noncoding RNAs. Cell 129: $1311-1323$.

Schmitges FW, Prusty AB, Faty $M$, Stutzer A, Lingaraju GM, Aiwazian J, Sack R, Hess D, Li L, Zhou S, et al. 2011. Histone methylation by PRC2 is inhibited by active chromatin marks. Mol Cell 42: 330-341.

Schuettengruber B, Chourrout D, Vervoort M, Leblanc B, Cavalli G. 2007. Genome regulation by polycomb and trithorax proteins. Cell 128: 735-745.

Shen X, Liu Y, Hsu YJ, Fujiwara Y, Kim J, Mao X, Yuan GC, Orkin SH. 2008. EZH1 mediates methylation on histone $\mathrm{H} 3$ lysine 27 and complements EZH2 in maintaining stem cell identity and executing pluripotency. Mol Cell 32: 491502.

Shen X, Kim W, Fujiwara Y, Simon MD, Liu Y, Mysliwiec MR, Yuan GC, Lee Y, Orkin SH. 2009. Jumonji modulates polycomb activity and self-renewal versus differentiation of stem cells. Cell 139: 1303-1314.

Simon MD, Chu F, Racki LR, de la Cruz CC, Burlingame AL, Panning B, Narlikar GJ, Shokat KM. 2007. The site-specific installation of methyl-lysine analogs into recombinant histones. Cell 128: 1003-1012.

Stojic L, Jasencakova Z, Prezioso C, Stutzer A, Bodega B, Pasini D, Klingberg R, Mozzetta C, Margueron R, Puri PL, Schwarzer D, Helin K, Fischle W, Orlando V. 2011. Chromatin regulated interchange between polycomb repressive complex 2 (PRC2)-Ezh2 and PRC2-Ezh1 complexes controls myogenin activation in skeletal muscle cells. Epigenetics Chromatin 4: 16.

Takeuchi T, Watanabe Y, Takano-Shimizu T, Kondo S. 2006. Roles of jumonji and jumonji family genes in chromatin regulation and development. Dev Dyn 235: 2449-2459. 
Tie F, Stratton CA, Kurzhals RL, Harte PJ. 2007. The N terminus of Drosophila ESC binds directly to histone $\mathrm{H} 3$ and is required for $\mathrm{E}(\mathrm{Z})$-dependent trimethylation of $\mathrm{H} 3$ lysine 27. Mol Cell Biol 27: 2014-2026.

Vermaak D, Wade PA, Jones PL, Shi YB, Wolffe AP. 1999. Functional analysis of the SIN3-histone deacetylase RPD3RbAp48-histone H4 connection in the Xenopus oocyte. Mol Cell Biol 19: 5847-5860.

Visser HP, Gunster MJ, Kluin-Nelemans HC, Manders EM, Raaphorst FM, Meijer CI, Willemze R, Otte AP. 2001. The Polycomb group protein EZH2 is upregulated in proliferating, cultured human mantle cell lymphoma. Br I Haematol 112: 950-958.

Voigt P, Tee WW, Reinberg D. 2013. A double take on bivalent promoters. Genes Dev 27: 1318-1338.

Wang L, Brown JL, Cao R, Zhang Y, Kassis JA, Jones RS. 2004. Hierarchical recruitment of polycomb group silencing complexes. Mol Cell 14: 637-646.

Zhang Z, Jones A, Sun CW, Li C, Chang CW, Joo HY, Dai Q, Mysliwiec MR, Wu LC, Guo Y, et al. 2011. PRC2 complexes with JARID2, MTF2, and esPRC2p48 in ES cells to modulate ES cell pluripotency and somatic cell reprogramming. Stem Cells 29: 229-240.

Zhao J, Sun BK, Erwin JA, Song JI, Lee JT. 2008. Polycomb proteins targeted by a short repeat RNA to the mouse X chromosome. Science 322: 750-756.

Zhao J, Ohsumi TK, Kung JT, Ogawa Y, Grau DJ, Sarma K, Song JJ, Kingston RE, Borowsky M, Lee JT. 2010. Genome-wide identification of polycomb-associated RNAs by RIP-seq. Mol Cell 40: 939-953. 


\section{Erratum}

Genes \& Development 27: 2663-2677 (2013)

Nucleosome-binding activities within JARID2 and EZH1 regulate the function of PRC2 on chromatin Jinsook Son, Steven S. Shen, Raphael Margueron, and Danny Reinberg

The Acknowledgments section for the above-mentioned article should also include funding support from New York State Stem Cell Science (NYSTEM), contract number C028105. 


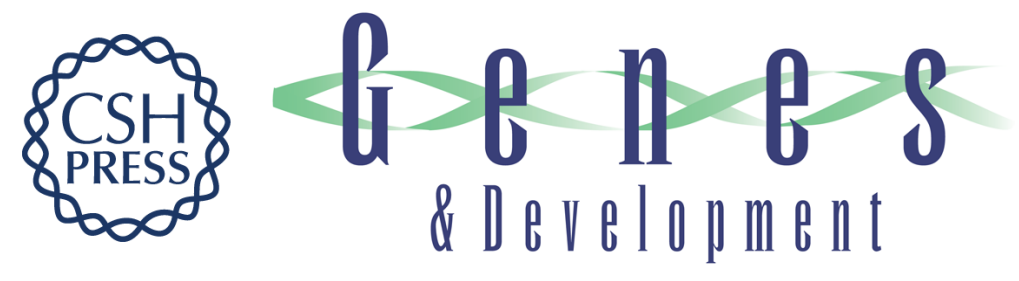

\section{Nucleosome-binding activities within JARID2 and EZH1 regulate the function of PRC2 on chromatin}

Jinsook Son, Steven S. Shen, Raphael Margueron, et al.

Genes Dev. 2013, 27:

Access the most recent version at doi:10.1101/gad.225888.113

\section{Supplemental http://genesdev.cshlp.org/content/suppl/2013/12/18/27.24.2663.DC1 \\ Material}

Related Content

Nucleosome-binding activities within JARID2 and EZH1 regulate the function of PRC2 on chromatin

Jinsook Son, Steven S. Shen, Raphael Margueron, et al.

Genes Dev. April , 2014 28: 921

References This article cites 52 articles, 18 of which can be accessed free at:

http://genesdev.cshlp.org/content/27/24/2663.full.html\#ref-list-1

Articles cited in:

http://genesdev.cshlp.org/content/27/24/2663.full.html\#related-urls

Creative This article is distributed exclusively by Cold Spring Harbor Laboratory Press for the first Commons six months after the full-issue publication date (see

License http://genesdev.cshlp.org/site/misc/terms.xhtml). After six months, it is available under a Creative Commons License (Attribution-NonCommercial 3.0 Unported), as described at http://creativecommons.org/licenses/by-nc/3.0/.

Email Alerting Receive free email alerts when new articles cite this article - sign up in the box at the top Service right corner of the article or click here.

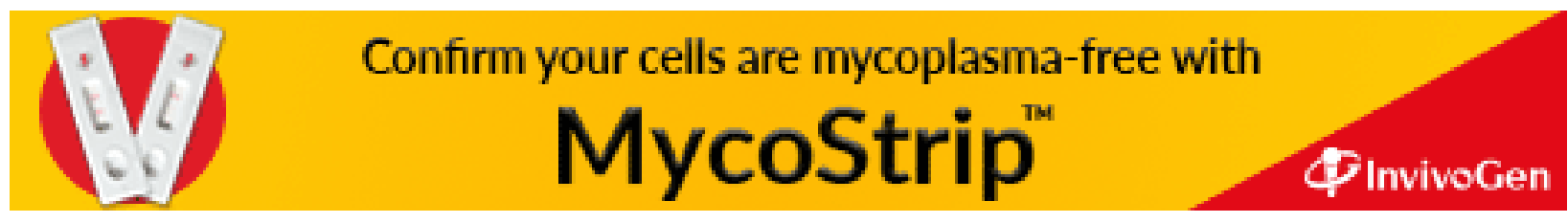

